\title{
Genetic Associations between Voltage-Gated Calcium Channels and Psychiatric Disorders
}

Arturo Andrade*, Ashton Brennecke, Shayna Mallat, Julian Brown, Juan Gomez-Rivadeneira, Natalie Czepiel, Laura Londrigan

Department of Biological Sciences, University of New Hampshire. 03824 Durham, NH, US. *Correspondence: Arturo.Andrade@unh.edu

\begin{abstract}
Psychiatric disorders are mental, behavioral or emotional disorders. These conditions are prevalent, one in four adults suffer from any type of psychiatric disorders world-wide. It has always been observed that psychiatric disorders have a genetic component, however new methods to sequence full genomes of large cohorts have identified with high precision genetic risk loci for these conditions. Psychiatric disorders include, but are not limited to, bipolar disorder, schizophrenia, autism spectrum disorder, anxiety disorders, major depressive disorder, and attention-deficit and hyperactivity disorder. Several risk loci for psychiatric disorders fall within genes that encode for voltage-gated calcium channels (Cavs). Calcium entering through Cavs is key for multiple neuronal processes. In this review, we will summarize recent findings that link Cavs and their auxiliary subunits to psychiatric disorders. First, we will provide a general overview of Cavs structure, classification, function, expression and pharmacology. Next, we will summarize tools and databases to study risk loci associated with psychiatric disorders. We will examine functional studies of risk variations in Cav genes when available. We will
\end{abstract}


review pharmacological evidence of the use of $\mathrm{Cav}$ modulators to treat psychiatric disorders. Our review will be of interest for those studying pathophysiological aspects of Cavs.

\section{KEYWORDS}

voltage-gated calcium channels; major depressive disorder; autism spectrum disorder; schizophrenia; bipolar disorder; attention-deficit and hyperactivity disorder; anxiety; calcium channel modulators; psychiatric disorders; auxiliary subunits; genetic risk variations

\section{Introduction}

Voltage-gated calcium channels (Cavs) are transmembrane protein activated by depolarization of membrane potential. The calcium that enters through Cavs is important for cellular processes including gene expression, hormone release, neurotransmitter release, cardiac muscle contraction, and pacemaker activity [1]. Some Cavs are multi-protein complexes comprised by the $\operatorname{Cav} \alpha_{1}$ pore-forming and the auxiliary subunits, $\operatorname{Cav} \alpha_{2} \delta$ and $\operatorname{Cav} \beta$. These auxiliary subunits have profound effects on the biophysical properties and membrane targeting of the $\mathrm{Cav} \alpha_{1}$ subunit [2,3]. Targeted deletions or disruptive mutations of genes encoding for $\mathrm{Cav}_{1}$, $\operatorname{Cav} \alpha_{2} \delta$ and $\operatorname{Cav} \beta$ result in deleterious effects, highlighting the importance of these genes [4-10]. Classically, dysfunction of Cavs has been linked to neurological disorders including Parkinson's disease, epilepsy, migraine, ataxia and neuropathic pain [11-17]. More recently, due to the advancement in genetic techniques to sequence and analyze full human genomes, genes encoding Cavs have been linked to psychiatric disorders $[1,17,18]$. All of this combined expands the relevance of Cavs in health and disease. 
Cavs are being considered as molecular targets to treat several neurological conditions including psychiatric disorders [17]. Furthermore, functional studies of Cav gene risk variations identified in patients with psychiatric disorders are providing mechanistic insights into these conditions. In this review, we will summarize literature on the structure and function of $\mathrm{Cav}$ genes, we will briefly overview some of the genetic tools that have allowed to establish genetic links between Cavs and psychiatric disorders, then we will examine studies that have linked Cav genes to several psychiatric disorders including bipolar disorder (BD), schizophrenia (SCZ), autism spectrum disorders (ASD), anxiety disorders, major depressive disorder (MDD), and attention-deficit and hyperactivity disorder (ADHD). If available, we will provide a summary of functional studies of risk variations for Cavs. Finally, we will synthesize the literature on therapeutic strategies that focus Cavs as pharmacological targets.

\section{Structure of voltage-gated calcium channels}

$C a_{V} \alpha_{1}$ subunits. Ten genes encode the Cav $\alpha_{1}$-pore-forming subunit of Cavs (CACNA1). Depending on their pharmacology and sequence similarity, $\operatorname{Cav} \alpha_{1}$ subunits are subdivided in three subfamilies (Cav1, Cav2 and Cav3) (Table 1) [2]. The Cav1 channel subfamily comprises Cav1.1 (CACNA1S), Cav1.2 (CACNA11C), Cav1.3 (CACNA1D) and Cav1.4 (CACNA1F) channels. Cav1 channels are sensitive to dihydropyridines (DHPs) and exhibit long-lasting activity relative to the members of $\mathrm{Cav} 2$ and $\mathrm{Cav} 3$, hence these channels are also known as Ltype [19]. 
The Cav2 channel subfamily is comprised of Cav2.1 (CACNA1A), Cav2.2 (CACNA1B), and Cav2.3 (CACNA1E). Cav2.1, Cav2.2, and Cav2.3 generate the P/Q-type, N-type and R-type currents respectively. These channels are generally localized in presynaptic terminals where they control calcium-dependent transmitter release in central and peripheral synapses, although Cav2.3 is also present in dendrites and extra postsynaptic sites [19]. Cav2 channels are selectively blocked with toxins. Cav2.1 is sensitive to $\omega$-agatoxin IVA, Cav2.2 to $\omega$-conotoxin GVIA, and Cav2.3 to SNX-482 [19].

The Cav3 subfamily comprises Cav3.1 (CACNAIG), Cav3.2 (CACNA1H), and Cav3.3 (CACNA1I), which generate T-type currents. Cav3 channels exhibit small single channel conductance, and relatively lower threshold of activation compared to all members of the Cav1 and Cav2 subfamilies (low voltage activation or LVA and high voltage activation or HVA, respectively) [20]. It is important to note that Cav1.3 channels exhibit a threshold of activation that is lower relative to the other members of the Cav1 subfamily and Cav2 channels, but slightly higher than all the Cav3 subfamily members [21]. All the CACNA1 genes undergo extensive alternative splicing that originates various splice variants with differences in their tissue expression, pharmacology and biophysical properties [22]. In some cases, the pharmacological and biophysical properties of a given splice variant overlaps with those ones from members of a different subfamily [23].

The primary structure of the Cav $\alpha_{1}$ pore-forming subunit is organized into four homologous domains (DI-IV). Each domain contains six membrane-spanning segments (S1-S6), with a re-entrant loop between S5 and S6, which contains negatively charged residues 
(glutamates and/or aspartates) that are essential for the selectivity filter. S4 contains positively charged residues (arginines) that function as voltage-sensors. The amino and carboxyl termini, as well as linker sequences between the DI-II, DII-III, and DIII-IV are all cytosolic. These sites are important for the interaction of $\mathrm{Cav}_{1}$ with intracellular proteins, as well as signaling cascades that regulate calcium entry through Cavs (Figure 1) [24].

Members of the Cav1 and Cav2 subfamilies form membrane complexes with the auxiliary subunits $\operatorname{Cav} \alpha_{2} \delta$ and $\operatorname{Cav} \beta$, influencing several biophysical and pharmacological properties of the Cav $\alpha_{1}$ subunit [2,3,24].

$C a_{V} \alpha_{2} \delta$ subunits. Four genes exist for the $\mathrm{Cav} \alpha_{2} \delta$ subunits (CACNA2D1-4), which encode for $\operatorname{Cav} \alpha_{2} \delta 1-4$ proteins [24]. Each $\operatorname{Cav} \alpha_{2} \delta$ subunit is translated from a single gene, which produces a protein that is cleaved into the $\alpha_{2}$ and $\delta$ peptides. A disulphide bond links these peptides $[25,26] . \mathrm{Cav} \alpha_{2} \delta$ is entirely extracellular but it is attached to the cell membrane by a glycosylphosphatidylinositol anchor (GPI) domain (Figure 1) [27]. Interestingly, the $\alpha_{2}$ peptide contains structural domains such as the von Willebrand Factor A domain (vWA) and two Cache domains [28]. The vWA domain in $\operatorname{Cav} \alpha_{2} \delta$ contains a metal-ion-adhesion site (MIDAS) that is important for membrane trafficking [29]. The functional role of the Cache domains is poorly understood [30,31]. $\mathrm{Cav}_{2} \alpha_{2} \delta-1$ and $\mathrm{Cav} \alpha_{2} \delta-2$ are targets for the gabapentinoid drugs gabapentin and pregabalin [32]. Similar to CACNA1 genes, CACNA2D genes are also subject to extensive alternative splicing that impacts affinity for gabapentin and other functions of $\mathrm{Cav}_{2} \delta$ subunits $[33,34]$. 
$C a_{V} \beta$ subunits. Four genes exist $\operatorname{Cav} \beta$ subunits (CACNB1-4), which encode for $\operatorname{Cav} \beta s$ (Cav $\beta 1-\beta 4) . \operatorname{Cav} \beta$ subunits are located in the cytoplasm (Figure 1); however, some splice variants of $\operatorname{Cav} \beta_{2}$ are attached to the membrane via a palmitoylation site $[35,36]$, and both $\operatorname{Cav} \beta_{3}$ and the splice variant $\mathrm{Cav} \beta_{4 c}$ can be mobilized to the nucleus [37-39]. $\mathrm{Cav} \beta$ subunits contain three conserved domains: an inactive guanylate kinase domain (GK), an src homology domain 3 (SH3), and a HOOK region [40-43]. The Cav $\beta-$ GK domain is important for the interaction with the AID domain in the I-II loop of the Cav $\alpha_{1}$ subunit [42]. The Cav $\beta-\mathrm{SH} 3$ and -HOOK domains mediate specific protein-protein interactions of $\operatorname{Cav} \beta$ subunits, for example, with dynamin [44]. All $C A C N B$ genes undergo alternative splicing [35].

\section{General function of voltage-gated calcium channels and auxiliary subunits}

$C a_{V} \alpha_{1}$ subunits. $\mathrm{Cav}$ channels are expressed in a wide variety of tissues where they serve specific functions. Cav1.1 is restricted to the skeletal muscle where the movement of the gating mechanisms induced by depolarization leads to opening of the ryanodine receptors (RYR), a class of calcium channels located in the sarcoplasmic membrane. The opening of RYR increases intracellular calcium, which results in activation of $\mathrm{Ca}^{2+}$-dependent contractile proteins [45]. Cav1.2 and Cav1.3 are broadly co-expressed in various tissues including the brain, heart, smooth muscle, and neurosecretory systems [1]. These two channels are important for gene expression, calcium transients in dendrites, and the coupling of electrical signals to hormone secretion [4650]. Cav1.2 controls contraction of heart muscle, and together with Cav1.3 controls the pacemaking activity of midbrain dopaminergic neurons and adrenal chromaffin cells [51-54]. 
Cav1.3 is key for the pacemaking firing of the sinoatrial node and for transmitter release from hair cells of the inner ear [55-57]. Cav1.4 controls glutamate release from photoreceptors $[58,59]$.

Cav2.1, Cav2.2, and Cav2.3 are involved in the release of neurotransmitters. Cav2.1 and Cav2.2 channels have a dominant role in the release of fast transmitters such as GABA, acetylcholine, and glutamate $[60,61]$. Cav2.2 channels are dominant in peripheral terminals that release glutamate and noradrenaline, as well as in central synapses that release dopamine, serotonin and noradrenaline [62-64]. Cav2.2 channels are also dominant in interneurons that express the cholecystokinin peptide $[65,66]$. Cav2.3 channels are present in the presynaptic terminals and dendrites of certain synapses of the central nervous system [67]. In the presynaptic terminals, Cav2.3 channels are localized in the active zones or in their periphery thereby controlling transmitter release [68]. In the dendrites, Cav2.3 channels control $\mathrm{Ca}^{2+}$-dependent spikes [69]. G-protein coupled receptors for several neurotransmitters including GABA, endogenous opioids, and endocannabinoids heavily regulate Cav2 channels [70,71]. This is an important negative feedback mechanism to limit the release of neurotransmitter [72,73]. Cav2 channels interact with soluble N-ethylmaleimide sensitive fusion protein receptors (SNAREs), which promote the fusion of secretory vesicles to the membrane in a $\mathrm{Ca}^{2+}$-dependent manner, this calcium generally enters through Cav2 channels [72].

Cav3.1, Cav3.2, and Cav3.3 channels control repetitive firing and pacemaking activity [20]. Cav3 channels open at relatively low voltages compared to members of the Cav1 and Cav2 subfamilies and have fast voltage-dependent inactivation. These unique biophysical properties 
underlie the role of $\mathrm{Cav} 3$ channels in rhythmic firing of action potentials [73,74]. Cav3 channels control the pacemaking activity of the sinoatrial node in the heart $[75,76]$, and the rhythmic bursts of action potential in relay neurons in the thalamus [77]. Cav3 channels are not known to be associated with the auxiliary subunits $\operatorname{Cav} \alpha_{2} \delta$ and $\operatorname{Cav} \beta$, however, recent evidence suggests that Cav3 channels interact with CACHD1, a protein closely related to the $\mathrm{Cav}_{2} \alpha_{2} \delta$ subunits (Table 1) [78-80].

$C a_{V} \alpha_{2} \delta$ subunits. $\mathrm{Cav} \alpha_{2} \delta-1$ is expressed in skeletal, cardiac and smooth muscle, secretory systems; central and peripheral neurons [32]. $\mathrm{Cav} \alpha_{2} \delta-2$ is abundantly expressed in the cerebellum, and to a lesser extent in other areas of the brain [6]. Cav $\alpha_{2} \delta-3$ is expressed throughout the central and peripheral nervous systems [81,82]. Finally, Cav $\alpha_{2} \delta-4$ expression is limited to the retina and endocrine tissue [83]. Expression of $\mathrm{Cav}_{v} \alpha_{2} \delta$ subunits increases membrane trafficking, stabilizes Cavs complexes in the cell surface and produces shifts in voltage-dependence of activation as well as inactivation $[2,30]$. $\mathrm{Cav}_{v} \alpha_{2} \delta$ subunits promote synaptogenesis by binding to thrombospondin [84], influence neurotransmission through interaction with $\alpha$-neurexins $[85,86]$, and affect synaptic plasticity by interacting with NMDA receptors [87].

$C a_{V} \beta$ subunits. $\operatorname{Cav} \beta$ subunits are broadly expressed in several tissues including brain, heart and skeletal muscle. These proteins promote trafficking of $\mathrm{Cav}_{1} \alpha_{1}$ to the cell surface by occluding endoplasmic reticulum retention signals present in the linker between DI and DII of $\mathrm{Cav}_{1}$ [88]. $\mathrm{Cav} \beta$ subunits are key for modulation of $\mathrm{Ca}_{v} 1$ and $\mathrm{Ca} 22$ channels by G-protein 
coupled receptors and other signaling complexes including Ras-related GTPases [89]. Cav $\beta 3$ and particularly $\mathrm{Cav} \beta 4$ are thought to induce gene expression $[37,39]$.

\section{Genetic analysis and tools to study psychiatric disorders}

Few cases exist where the inheritance of a disorder involving Cav genes follow mendelian models. However, spinal cerebellar ataxia 6 (SCA6) and Timothy Syndrome (TS) are two cases that follow an autosomal dominant pattern. Alterations in the CACNA1A and CACNA1C genes underlie SCA6 and TS, respectively [90,91]. In SCA6, the CACNA1A gene contains between 20 and 33 CAG repeats that encode for glutamines in the C-terminus [92]. Although the molecular mechanism by which these repeats lead to the disease remains to be fully understood, current evidence suggests transcriptional dysregulation mediated by a Cav2.1 Cterminus fragment with the glutamine repeats [93]. In TS, mutations in CACNA1C (G402S and G406R) produce Cav1.2 channels with gain of function $[94,95]$. TS is a condition that affects the heart and the nervous system. Patients with Timothy syndrome present several characteristics seen in patients with ASD [91]. Recent evidence suggests that Cav1.2 mutations underlying TS produce defects in neuronal migration during cortical development [96]. In contrast to SCA6 and TS, most psychiatric disorders are genetically complex conditions that involve the interaction among several genes and their interactions with the environment [97,98].

Several genetic methods have been used to determine the genes or set of genes that are likely to underlie psychiatric disorders. Historically, linkage and linkage-disequilibrium studies provided the initial evidence of the genetic origins of psychiatric disorders $[99,100]$. However, it 
is now possible to perform genetic analysis using whole genomes from large populations through genome-wide association studies (GWAS) to discover new risk variations associated with psychiatric disorders [101] .

Linkage studies. Evidence for linkage is derived from observing the cosegregation of specific genomic regions with a given disorder. As such, this method is most effective for the study of disorders inherited in a Mendelian fashion. Pedigrees containing multiple generations of genetic data can be used to elucidate inheritance patterns and map potential genomic risk loci for a given disorder. The identification of large families with high prevalence of a given condition often facilitates linkage studies. In these studies, the inheritance of a genetic loci can be correlated with the presence or absence of the disorder [99].

Linkage-disequilibrium studies. In these studies, the aim is to map a nonrandom association of alleles at two or more loci to discover disease haplotypes. These haplotypes are thought to be inherited from one or a few founding members of isolated populations. [102].

Association Studies. Here the goal is to find risk loci for a specific condition by assessing correlations between disease status and genetic variation. Of the association studies, GWAS are becoming a popular method to screen markers or genetic variations of disease across whole genomes of large populations. GWAS have identified several genetic variations of Cav genes linked to BD, SCZ, ASD, ADHD, and MDD [17,18]. We will review several of these cases below. Thanks to GWAS data many new risk loci for psychiatric disorders have been found $[103,104]$. 
All the genetic approaches mentioned above have helped to identify associations of several gene variations to psychiatric disorders. These variations include single nucleotide polymorphisms (SNPs), small indels, copy number variations (CNVs), de novo variations, and large chromosomal rearrangements [105].

Our understanding of psychiatric disorders is evolving towards a more comprehensive analysis that includes genetic, genomic, functional and behavioral studies. These are possible thanks to tools that allow to screen multiple patients (probands) and their corresponding unaffected relatives. Among these tools are next-generation sequencing, microarrays, endophenotype analysis, gene network analysis and computational modeling [105].

Next generation sequencing (NGS). These tools include whole exome and genome sequencing (WES and WGS, respectively), as well as RNA sequencing (RNA-seq). WES detects genetic variations through capture and sequencing of coding regions within the genomic DNA. Since most of the genome is noncoding, this approach greatly reduces the amount of sequencing to $\sim 2 \%$ of the whole genome [106]. WGS offers an almost complete sequence coverage ( 95\%) that includes coding and non-coding regions and is more powerful to detect exome variations than WES. This increased coverage enables identification of non-coding regions that include splicing regulatory elements, promoters, enhancers, sites that regulate RNA transport and stability [107]. WES are more commonly used in genetic screenings for psychiatric disorders because of their lower cost compared to WGS [108]. Nevertheless, WES studies allow to focus on regions where variations can be identified and interpreted faster than in WGS studies [108]. 
RNA-seq is a common tool used for genetic analysis of psychiatric disorders. This technology enables quantification of gene expression, detection and quantification of exon splicing, quantification of rare transcripts and non-coding RNAs, and detection of genome rearrangements. In summary, RNA-seq provides a whole transcriptome landscape with high signal to noise ratio and with small amount of RNA input [109].

Microarrays. Studies using microarrays are commonly used to identify genetic risk variations that involve structural changes $>1000 \mathrm{bp}[105,110]$. Large structural variations detected by microarrays are thought to increase the risk SCZ, ASD, and ADHD [111-117].

Gene network analysis. The discovery of risk variations associated with psychiatric disorders has been a stepping stone to elucidate the molecular mechanisms that underlie these conditions. Now the challenge is integrating this information to understand how genetic variation influence complex disorders and traits $[118,119]$. It is thought that complex interaction of genes in a network are more likely to explain phenotypes of psychiatry disorders, rather than the additive effect of those genes. Complex interaction of genes within networks include transcriptional regulatory, protein-protein interaction, metabolomic networks, and a hierarchical interaction with other gene networks [120-123]. Furthermore, complex interactions between gene networks with the environment are becoming increasingly important to fully explain phenotypes linked to psychiatric disorders [124-129]. 
Endophenotypes. Despite recent advances linking genetic risk variations to psychiatric disorders, the phenotypic consequences of those variations are poorly understood. However, a combination of molecular genetics with endophenotypes might represent a promising approach to understand the behavioral links between risk variations and psychiatric disorders [130]. Endophenotypes are quantitative neurobehavioral traits that are associated with a disorder, are reasonably heritable, co-segregate with the disease and are independent of the clinical status of the disorder [131]. Endophenotypes provide clinical measures of disease diagnosis and progression. Examples of endophenotypes include deficits in pre-pulse inhibition and sensory gating, decline in working memory, and deficits in face emotion labeling $[130,131]$. Interestingly, the latter has been associated with $C A C N A 1 C$ in patients with bipolar disorder [132].

Computational psychiatry. Mathematical approaches are being used to integrate findings derived from genetic screenings, functional studies of gene risk variations, and behavioral phenotypes. Computational psychiatry is an emerging field that aims to model the compounded effects of individual genes, as well as their interaction with other genes (gene networks) and with the environment using mathematics [133-136]. Computational approaches have been successfully used to provide insightful mechanisms for disorders such as SCZ, ASD, and ADHD [137-139].

\section{Overview of databases and resources to study the links between genetic risk variations and psychiatric disorders.}


To integrate genetic studies with phenotypes, an extensive collaboration between 15 research institutions to study functional genomics was performed, and the product of this collaboration is PsychEncode (http://www.psychencode.org/) [140]. PsychEncode is a public resource that contains multi-dimensional genomic relevant data from multiple consortia, singlecell studies and relevant data from functional characterization performed in model systems of regulatory elements and variations associated with disease $[141,142]$. The data captured within PsychENCODE includes a catalog of non-coding regulatory elements, epigenetic modification, and gene expression data from tissue- and cell-specific samples. In addition to human data, PsychENCODE includes data from mouse brain and reprogrammed induced pluripotent stem cells as model systems to provide integrative and functional analysis of disease [141,143].

PsychEncode merges data relevant to the brain from other databases including The Encyclopedia of DNA Elements (ENCODE), CommonMind Consortium (CMC), RoadMap Epigenomics Mapping Consortium (REMC), Genotype-Tissue Expression project (GTEx), and single-cell studies. The ENCODE project (http://www.encodeproject.org/) seeks to describe and annotate functional genetic and genomic elements from all tissue and cell-types from model organisms and humans [144,145]. CMC (http://www.synapse.org/CMC) contains information on large-scale genomic data from human subjects with psychiatric disorders [142]. REMC (http://www.roadmapepigenomics.org/) is a repository of healthy ex vivo tissue and cell sample data designed to provide a comprehensive epigenetic map for disease-focused research [146]. GTEx (http://gtexportal.org) project utilizes tissue samples from post-mortem donors taken from more than 40 different types of tissue from each donor to compile a tissue-specific map of gene 
expression, gene variance, and gene regulation within and between individuals. From GTEx, it is possible to analyze human expression Quantitative Trait Loci (eQTL) $[119,147,148]$.

\section{Genetic associations between Cav genes and psychiatric disorders}

Gene network analyses have consistently implicated Cav genes in psychiatric disorders, which nicely correlates with the role calcium signaling in neuronal function $[17,18]$. In this section, we will review several large studies that have provided strong evidence linking Cav genes to psychiatric disorders and related endophenotypes. We will also briefly describe functional studies, when available, of risk variations for $\mathrm{Cav}$ genes.

a) CACNA1C

CACNA1C encodes Cav1.2, an ion channel that has been extensively studied in the heart. Here Cav1.2 channels tightly couple depolarization to muscle contraction through activation of RYR located in the ER of cardiomyocytes [149]. Additional studies have demonstrated that Cav1.2 is expressed in postsynaptic terminals in the brain, and together with Cav1.3, influences neuronal firing and couples excitation to gene expression [150]. The activity of neuronal Cav1.2 and Cav1.3 channels are implicated in several processes relevant to psychiatric disorders including learning, memory, and brain development [151,152]. Risk variations in CACNAIC have been found in several association studies of BD, and evidence suggest that some of CACNAIC variations are risk for SCZ, MDD, ADHD, and ASD. 
Several SNPs in CACNAIC have been linked to psychiatric disorders with most of them being located in a large intron $(\sim 330 \mathrm{~kb})$ between exons 3 and 4 (intron 3). Significant association of the SNP rs1006737 to BD was originally found in a European cohort (> 4300 cases and >6000 controls) [153]. Associations of this SNP with BD have been replicated in several other studies, furthermore significant association of rs 100637 with SCZ, ADHD and MDD has also been detected [154-156]. At the molecular level, rs100637 is correlated with changes in CACNAIC expression, including decreased expression in the cerebellum [157], but increased expression in the dorsolateral prefrontal cortex and induced human neurons $[132,158]$. The latter observation correlates with increased L-type currents seen in induced human neurons derived from individuals carrying rs1006737 [158]. Furthermore, the minor allele for rs 1006737 (A) is associated with increased methylation of $\mathrm{CpG}$ islands located within intron 3 [159]. Imaging studies have shown associations of rs 1006737 with changes in structure and activity of brain regions related to emotion processing, memory formation and cognition, including hippocampus, inferior occipital fusiform gyrus, prefrontal cortex and amygdala [132,160,161]. For example, carriers of rs 1006737 show greater thickness of the medial orbitofrontal cortex than non-carriers, and the presence of this SNP correlates with age-related caudal anterior cingulate cortex thickening [161]. In addition, two independent studies have shown that rs1006737 is associated with increased amygdala volumes in adults and adolescents $[162,163]$. Behavioral studies in humans suggest that rs1006737 is linked to facial emotion recognition in both healthy individuals and patients with BD $[164,165]$. Some studies suggest that rs 1006737 is also associated with borderline personality disorder in females, but not males [166,167]. rs 1006737 has significant association with reduced baseline affective startle modulation in healthy males. 
Alterations in this endophenotype have been observed in severely depressed and anxious patients, as well as patients with $\mathrm{BD}$ in remission [168].

As mentioned above, rs1006737 has also shown strong associations with SCZ. Additive interaction of the SNP rs 1006737 CACNAIC with rs1344706 in the zinc finger protein 804A gene (ZNF804A) has been linked to defects in white matter microstructure and psychosis [169], although the effect of rs1344706 is thought to be larger than rs1006737. In MDD, rs1006737 was associated with less baseline depressive severity [170]. Furthermore, rs 1006737 showed biphasic association with antidepressant treatment in a European population. The A allele was associated with a better outcome of antidepressant treatment, but it shows the opposite association in a group of individuals with treatment-resistant depression [171].

The SNP rs2007044 has been associated with SCZ in several studies including Asian, East Asian, European and Ashkenazi Jew populations [172-176]. This SNP was associated with decreased functional connectivity between the right dorsolateral prefrontal cortex and right superior occipital gyrus/cuneus, as well as the anterior cingulate cortex; and at the behavioral level with poor working memory performance [177]. rs2007044 is also associated with increased concentrations of glutamate, glutamine and glutamate plus glutamine in subcortical regions. These observations have been reported in patients with SCZ, especially in subjects at risk of psychosis [178].

Sleep disturbance is consistently reported in patients with psychiatric disorders including SCZ, BD and MDD [179-181]. CACNAIC variations in intron 3 have been linked to sleep traits 
such as narcolepsy (rs10774044), sleep latency and sleep quality (rs7316184, rs7304986, rs7301906, rs16929275, rs16929276, rs16929278, rs2051990) [182-184]. The SCZ risk variations in CACNA1C (rs4765913, rs4765914, and rs2239063) are associated with sleep latency in infants [185]. rs4765914, together with rs7297582, was identified in two independent studies as genetic risks for BD, MDD, and SCZ [155,186].

Other SNPs in CACNA1C have been linked to several psychiatric conditions. The SNP rs73248708 (intron 3) and rs116625684 (intron 1) were not associated with SCZ or other psychiatric disorders, they affect the risk of developing depressive symptoms upon exposure to adult severe trauma in adulthood [187]. The SNP rs 10848635 was identified in a Korean and in a Taiwanese population as risk factor for SCZ and BD, respectively [188,189]. Associations of rs 10848635 with efficacy of the anti-depressant citalopram were also found [171]. The SNP rs4765913 was identified in two independent GWAS of European cohorts as genetic risk for BD [190,191]. rs 10848653 and rs2239118 were identified using a family-based association test (parent/affected child trios) been linked to ASD, this study also identified SNPs in CACNAIG (see below) [190,191].

In addition to variations with mendelian inheritances (TS) and SNPs associated to psychiatric disorders, two de novo missense variations in CACNA1C were identified in a large whole-exome sequencing study using massively parallel short-read sequences of more than 2500 patients with SCZ and more than 2500 control subjects in a Swedish population [192]. One risk variant $(\mathrm{G} / \mathrm{T})$ is predicted to alter a canonical splice donor site for exon 21 , which is part of a pair 
of mutually exclusive exons (together with exon 22), with exon 21 being dominant in the brain [22]. The second risk variant $(\mathrm{C} / \mathrm{T})$ introduces a premature stop codon [18].

b) CACNA1D

The CACNA1D gene encodes Cav1.3. This channel contributes to the rhythmic activity of the sinoatrial node and is thereby involved in the regulation of heart rate [54]. As stated above, Cav1.3 shares some functions with Cav1.2 in the brain. However, Cav1.3 is the main contributor to the pacemaking activity of dopaminergic neurons in the substantia nigra [54]. Risk variations in $C A C N A 1 D$ have been associated with BD, SCZ, ADHD, MDD, and ASD. The non-coding SNP rs893363, located in the 3' UTR of CACNA1D and the putative promoter region of the choline dehydrogenase gene $(C H D H)$, was found in a genome-wide analysis of five major psychiatric disorders including BD, SCZ, ADHD, MDD, and ASD [155]. In a study with samples from a cohort of European-American individuals, 111 non-coding variations in regulatory elements that are predicted to modify binding of transcription factors to genomic regions of CACNA1D show significant association with BD [193]. Furthermore, two coding variations in CACNA1D (A1751P and R1771W) segregate with BD type I cases in a large pedigree [194]. Although a study in a Han Chinese population found no association between CACNA1D SNPs and SCZ [195], more recent studies that include larger populations of East Asian, Chinese, European and Ashkenazi Jewish individuals identified the SNP rs2358740 located in a putative promoter region for $C A C N A 1 D$ and the mRNA decapping enzyme $1 \mathrm{~A}$ gene (DCP1A) as a risk variant for SCZ [173,196,197]. 
Several studies point to links between $C A C N A 1 D$ and ASD. Through whole-exome sequencing three de novo missense variations in CACNA1D (A749G, G407R, and V401L) were identified as genetic risks for patients with sporadic autism and intellectual disability [198-200]. These genetic risk variations produce a gain of function of Cav1.3 channels [201-203]. Additional variations (A59V, S199L and R2021H) were also identified in using WES. The A59V maps to an $\mathrm{N}$-terminal region of Cav1.3 that is key for calcium-dependent inactivation. S1977L and R2021H map to a proline-rich domain of the C-terminus that interacts with SH3 And Multiple Ankyrin Repeat Domain 3 protein (Shank3). Interestingly, SHANK3 is another gene strongly linked to ASD [204]. The gene CACNA1D is subject to alternative splicing. Interestingly alterations in the relative abundance of several alternatively spliced exons in CACNA1D have been observed cortical samples of patients with ASD [205]. Finally, the variation Q567H is linked to moderate hearing impairment and intellectual disability, this variation results in a loss of function [206].

Although risk variations in CACNAIS and CACNAIF have been identified in GWAS and WES studies for BD and SCZ, we will not review them here because the expression of these two genes in the brain is extremely rare relative to the other Cav genes, therefore the links their corresponding risk variations to psychiatric disorders are hard to infer [18].

c) $C A C N A 1 A$

CACNA1A is the most dominant presynaptic calcium channel in central synapses, particularly those ones from Purkinje cells in the cerebellum and excitatory synapses of cortex 
and hippocampus. Various mutations in $C A C N A 1 A$, causing gain or loss of function, have been found in patients with hemiplegic migraine 1 (FHM-1), Episodic Ataxia 2 (EA-2), SCA-6, and epilepsy [14]. More recently, a clinical recharacterization of patients with EA-2 and SCA-6 showed that they also present delayed development, endophenotypes related to learning disabilities, ASD and ADHD [207]. In another study, some FHM-1 and EA-2 patients also presented SCZ, learning disabilities and ADHD [208]. Furthermore, analysis of the splice isoform landscape across several psychiatric disorders show that alternative splicing of CACNA1A is altered in ASD [209]. Finally, rs10409541 was among the top 15 most contributory SNPs for ASD diagnosis prediction in a Central European population [191].

\section{d) $C A C N A 1 B$}

$C A C N A 1 B$ encodes Cav2.2 channels, which are dominant in presynaptic terminals of dorsal root ganglia and superior cervical ganglia, as well as some interneurons, and dopaminergic neurons of the midbrain. Several studies have linked $C A C N A 1 B$ to SCZ, but also some $C A C N A 1 B$ risk variations are associated with $\mathrm{BD}$ and $\mathrm{ASD}$. Purcell, et al. identified a de novo variation (G/A) in patients with $\mathrm{SCZ}$ that introduces a premature stop codon in $C A C N A 1 B$ [192]. The intronic SNPs, rs7036881 and rs78178087, in CACNA1B have been found to be weakly associated with SCZ and the antipsychotic efficacy of paliperidone palmitate in a study with European patients [210]. In line with this, another study in a South African population found that the rs2229949 is linked to improved negative symptomatology during antipsychotic treatment [211]. Deletions in $C A C N A 1 B$ were detected in 16 patients and duplications of this same gene in 10 patients with SCZ [212]. 
Several studies have reported that $C A C N A 1 B$ is linked to ASD, MDD, and BD. A monogenic duplication in $C A C N A 1 B$ has been linked to Asperger Syndrome, a condition that is part of ASD [213]. Pathway analysis of variations linked to ASD has shown that $C A C N A 1 B$, together with $C A C N A I C$ and $C A C N A I F$, converges on MAP kinase/cellular signaling and neuronal development/axon guidance [214]. CACNA1B, together with CACNA1C and CACNA2D4, has been also associated with suicide risk in patients with MDD [215]. Finally, WES of 200 individuals from 41 families identified 50 non-coding variations in CACNA1B that increase the risk for BD [193].

e) CACNAIE

CACNA1E encodes the Cav2.3 or R-type channels. Cav2.3 channels are broadly expressed throughout the nervous system and are located in presynaptic terminals, dendritic spines, and some extrasynaptic sites [67]. variations in the CACNAIE gene have been linked to ASD, MDD, SCZ, as well as some endophenotypes related to these conditions. In a study comprising 209 families with no previous history of ASD, parent-child with sporadic autism trios and unaffected siblings were sequenced and a de novo variant in CACNA1E (G1209S) was identified in one patient [198]. A second de novo synonymous variation in CACNAIE located near a splice site and is predicted to affect an exonic spicing regulator was identified in another patient with ASD [216]. In a genome-wide meta-analysis study of more than 135,000 cases with more than 340,000 controls, 44 significant risk loci for MDD were identified, including CACNA1E [217]. The SNP rs4652676 was linked to neuroticism and subjective well-being, 
which are endophenotypes associated with MDD [218]. The SNP rs704329 is implicated in the efficacy of serotonin reuptake inhibitors (SSRIs) in a Taiwanese population [219]. Similar to several other CACNA1 genes, CACNA1E has been associated with $\mathrm{SCZ}$ as well as working memory related to cortex and cerebellum [155,220].

\section{f) $C A C N A 1 G$}

CACNA1G encodes the Cav3.1, a T-type channel member of the Cav3 subfamily. Previous studies have identified risk variations of $C A C N A 1 G$ as genetic risk for ASD. A linkage study of sibling pairs with only male probands found a strong association of the chromosomic region 17q11-21, which contains among other genes, $C A C N A 1 G$ [216]. A later study confirmed CACNAIG as a novel candidate gene for ASD by identifying several SNPs within intron 9 with the strongest association relative to other genes present in the 17q11-21 region [221]. rs 198538 and rs198545, together with some CACNA1C SNPs, were identified as risk variations for ASD [190]. Furthermore, a de novo synonymous variation in CACNAIG was identified in exome sequencing of 343 families with one proband and at least one unaffected sibling [199,222]. A de novo variation screening in childhood-onset cerebellar atrophy identified various disruptive variations in $C A C N A 1 G$, some patients with this pathology exhibit autistic traits [223]. However new studies using transcriptome-wide association, which integrated GWAS with gene expression predictors from several databases from adult and fetal human brain, found no evidence of association between CACNAIG and ASD [224].

\section{g) $\mathrm{CACNAIH}$}


The CACNA1H gene encodes the Cav3.2 channel, also a T-type channel. This gene is normally associated with idiopathic epilepsy. However, multiple studies have found associations of CACNA1H with ASD and SCZ. Four missense variations (R212C, R902W, W962C and A1874V) were identified in a study of 461 probands with ASD and 480 ethnically matched individuals by targeted sequencing of the $C A C N A 1 H$ genomic region [225,226]. Functional analysis revealed that these variations produce loss of function of $\mathrm{Cav} 3.2$ by reducing channel conductance, and/or shifting voltage-dependence of activation in the depolarizing direction [225]. However, these variations have low penetrance, and some of them were also found in unaffected individuals [225]. In a more recent study using ultra deep sequencing of 78 ASD candidate genes in the cerebellum and cortical samples of several ASD cases and neurotypical controls, a synonymous $C A C N A 1 H$ variation was found in the frontal cortex but not in cerebellum [227]. In this same study, a missense variation (S1970C) was identified in a female diagnosed with ASD [227]. WES from more than 10,000 parents with only one child with ASD found de novo missense variations in CACNAIH [199,228]. Furthermore, a study of 262 patients with their unaffected parents from Japan identified a disruptive de novo missense variations in CACNA1H (R1189C) [229]. All of these studies support that CACNA1H is a susceptibility gene for ASD.

Two rare disruptive variations ( $7 \mathrm{bp}$ and $2 \mathrm{bp}$ deletions) for $C A C N A 1 H$ that are predicted to produce a frameshift were found in patients with SCZ [192]. Furthermore, a GWAS performed in a Swedish population, followed by a meta-analysis with previously identified genes associated with SCZ, found association of CACNA1H with this condition [230]. 


\section{h) CACNAII}

CACNA1I encodes Cav3.3 channels, the third T-type channel member of the Cav3 subfamily. Of the Cav3 members, Cav3.3 channels have the most depolarized threshold of activation, as well as the slowest opening and inactivation rate [20]. Cav3.3 channels regulate sleep spindles, which have been shown to be altered in patients with SCZ [181]. Not surprisingly, several studies have strongly linked CACNAII to SCZ and related endophenotypes. Additional evidence also suggests risk variations of CACNA1I for ADHD and ASD.

Two rare, de novo missense variations of CACNA1I (R1346H and T797M) were identified by exome sequencing of trio samples that included 105 probands, parents, and unaffected siblings when available [231]. Cav3.3 was the only gene with more than one variation [231]. In particular, R1346H impairs N-glycosylation of Cav3.3 channels preventing membrane targeting and thereby reducing overall calcium currents [232]. The functional consequences of T797M are unknown, however this mutant produces similar calcium currents relative to WT [232]. A study by the SCZ working group of the PGC validated CACNA1I as a risk gene for SCZ [172]. This claim has been supported in other GWAS. The intergenic SNPs between RPS19BP1 and CACNA1I, rs5757717 and rs9611198, were found in a GWA study of an Ashkenazi Jewish population and an Irish population respectively [173,233]. The intronic SNP rs3788567 was identified with very high significance in an Ashkenazi Jewish population [173]. In a study of an Uyghur Chinese population that comprised 985 patients and 1218 neurotypical controls, six SNPs within CACNAII were significantly associated with SCZ (rs132575, 
rs136805, rs713860, rs738168, rs5757760, rs575087) [234]. Furthermore, rs4522708, rs3788568, rs5750862 were significantly associated with SCZ in a Han Chinese population [235,236]. Interestingly, rs4522708 was also found in a study of a European population [172]. CACNAII has been also associated with endophenotypes related to SCZ, such as cognitive ability and sleep spindle activity. A genome wide meta-analysis study identified an association of CACNA1I with cognitive ability [237]. The genomic region Chr22: 39975017:40016914, which spans across CACNAII was associated with higher amplitude, longer duration and higher intensity of slow spindles in healthy adolescents [238].

A recent GWAS linked the rs199694726 in CACNA1I to impulsive behavior under extreme negative emotions [239]. Impulsive traits are a common endophenotype related to psychiatric disorders including ADHD [240]. Furthermore, a study containing 1,013 probands of European descent at the Children's Hospital of Philadelphia (CHOP) found a CACNAII CNV (large deletion) associated with ADHD [241]. CACNAII was also identified as a risk gene for ASD in the family-based association test [242]. The SNP rs5750860 was significantly associated to ASD in an another GWAS [190].

\section{Genetic associations between $\operatorname{Cav} \alpha_{2} \delta$ and $\operatorname{Cav} \beta$ auxiliary subunits and psychiatric disorders}

In the previous section we summarized strong evidence linking several genes that encode Cav $\alpha_{1}$ pore-forming subunits to psychiatric disorders. Given that the auxiliary subunits, $\operatorname{Cav} \alpha_{2} \delta$ and $\operatorname{Cav} \beta$, heavily influence membrane targeting and overall activity of Cav $\alpha_{1}$, genes encoding 
these subunits are also strongly linked to psychiatric disorders. In this section, we will describe current studies associating the genes for $\operatorname{Cav} \alpha_{2} \delta$ and $\operatorname{Cav} \beta$ with multiple psychiatric disorders.

\section{a) CACNA2D1}

The $C A C N A 2 D 1$ gene encodes the $\mathrm{Cav} \alpha_{2} \delta-1$ subunit. This subunit is highly expressed in skeletal muscle, the brain and peripheral nervous system [79], and some studies suggest that it is enriched in glutamatergic neurons [243]. Various genetic studies have implicated the CACNA2D1 gene in psychiatric disorders including MDD, BD and SCZ. The genome-wide association metanalysis of MDD that identified $C A C N A 1 E$, also found $C A C N A 2 D 1$ as potentially druggable target for this condition [217]. Furthermore, in a genome-wide association environment study, a suggestive association was found for rs17156280 in CACNA2D1 with an interaction between depressive state and stressful events [244]. A strong association with depressive traits including subjective well-being and neuroticism was found for the SNPs in CACNA2D1, rs258668 and rs258677 [218].

A metanalysis of data collected by the Bipolar Disorder Genome Study Consortium identified rs2367911 as a risk SNP for BD with comorbid binge eating. Indeed, networks/interactomes for $C A C N A 2 D 1$ and apolipoprotein B gene $(A P O B)$ were the top two hits for BD and binge eating in this study [245]. The same study that identified risk variations for CACNA1C and other Cav genes in a Swedish population, found a disruptive variation in CACNA2D1 that produces a frameshift associated with SCZ [192]. A study in a Japanese population a found CNV for CACNA2D1 (a large deletion) in one patient with SCZ [118]. 


\section{b) $C A C N A 2 D 2$}

$C A C N A 2 D 2$ encodes $\operatorname{Cav} \alpha_{2} \delta-2$. Although this protein is broadly expressed in the central nervous system, there is higher expression in the cerebellum relative to other areas of the brain, particularly in Purkinje cells [30]. In cortical tissue, some studies suggest that $\mathrm{Cav}_{2} \delta-2$ is more abundant in interneurons than in glutamatergic neurons [243]. Purcell et al, found three de novo variations in CACNA2D2 in patients with SCZ. Two of these three variations introduced premature stop codons, and a the third one is predicted to disrupt a splice donor site [194]. A CACNA2D2 variation (A900T) scored as a putative second hit in a study of 558 patients with SCZ in a Spanish population [246].

c) CACNA2D3

$C A C N A 2 D 3$ encodes $\operatorname{Cav} \alpha_{2} \delta-3$. This protein was initially characterized as a target to treat pain, however recent studies suggest that the CACNA2D3 is strongly linked to ASD, and to a lesser extent, SCZ and BD. The same WES that identified variations in CACNA1G, found another variation in $C A C N A 2 D 3$ that is predicted to disrupt a splice junction $(A / G)[222]$. An inherited variation with splicing disruption was identified in a study of 2,066 unique families with children diagnosed with ASD, the cohort consisted of 2,618 children with ASD (1,740 probands and 878 unaffected siblings) [247] . Furthermore, a de novo variation (E508Stop) predicting loss of function of $\mathrm{Cav}_{2} \alpha_{2} \delta-3$ was found in two patients in an exome sequencing study that included 3871 ASD cases and 9937 ancestry controls. This study also identified several 
inherited variations in CACNA2D3 which effect is unknown [248]. Analysis of CNVs in a study containing samples from 2,478 families with children affected with ASD identified through the Simons Simplex Collection found association to a deletion in CACNA2D3 [249]. In a study where 208 candidate genes were sequenced in 11,730 cases and 2,867 controls, two de novo missense on CACNA2D3 were identified (A773V and A275T) [250]. The SNP rs3773540 was among the top 15 SNPs contributing to ASD diagnosis as predicted by gene set enrichment analysis [191]. Analysis of data from the Hartwell Autism Research and Technology Initiative (iHART) has further confirmed that CACNA2D3 is a risk gene for ASD [250].

Previous studies have shown that the $3 \mathrm{p} 14$ genetic region is associated with SCZ and with an endophenotype related to the function of the temporal lobe, the antisaccade reflex. Interestingly, this genomic region contains CACNA2D3 [251]. Pathway analysis of SNPs with significant risk for SCZ suggest association of CACNA2D3 with the response to lurasidone, an antipsychotic used to treat SCZ [252]. Also, the genomic region 3p21.1_1 is enriched in for both $\mathrm{SCZ}$ and $\mathrm{BD}$, this region contains $C A C N A 1 D$ and $C A C N A 2 D 3$ among six different genes [253]. The SNP rs9849795 located in CACNA2D3 is associated with functional brain connectivity inferred by functional magnetic resonance, this trait thought to be compromised in BD and SCZ, this study also identified association with SNPs in CACNA1C, CACNA2D4 and CACNB2 [254].

\section{d) $C A C N A 2 D 4$}

$C A C N A 2 D 4$ encodes the $\mathrm{Cav} \alpha_{2} \delta-4$ subunit. This protein is abundantly expressed in the retina, but it is also found in pituitary and adrenal glands $[83,255]$. Despite the relatively low 
expression of $\mathrm{Cav} \alpha_{2} \delta-4$ in the brain compared with other auxiliary subunits, several studies have identified the CACNA2D4 as a risk gene for some psychiatric disorders.

The SNP rs 1024582 located between $C A C N A 2 D 4$ and $C A C N A 1 C$ was found highly significant in a cross-disorder study that included ADHD, BD, ASD, SCZ and MDD [155]. In a later study by Purcell et al, a de novo variation that produces a frameshift in CACNA2D4 was identified in patients with SCZ [192]. The SNP rs4765847 was found to associate with DMN, an endophenotype of SCZ [254]. Furthermore, partial deletions of $35.7 \mathrm{~kb}$ in CACNA2D4 was found in two unrelated patients with late onset BD I and one in control individuals [256]. These three deletions eliminate exons 17-26 in CACNA2D4, which comprise most of the Cache domain [256]. In a linkage disequilibrium study to detect SNP-SNP interactions that are common in complex diseases a single interaction between SNPs located near RYR2 and CACNA2D4 was found in samples of the Wellcome Trust Case Control Consortium (WTCCC) [257].

Genetic associations of $C A C N A 2 D 4$ with MDD and ASD have been also identified. In a WES study in brain samples of suicide victims suffering from MDD and control subjects with MDD who died from other causes, a variation in a splice donor (C/A) in CACNA2D4 was identified [215]. For ASD, a rare homozygous deletion was detected in a male proband that is predicted to affect $C A C N A 1 C$ and CACNA2D4 (12p13.33) [258].

e) $C A C N B 1$ 
$C A C N B 1$ encodes for $\operatorname{Cav} \beta_{1}$. A splice variant of this subunit was originally identified in skeletal muscle $\left(\operatorname{Cav} \beta_{1 a}\right)$ as the only partner of $\mathrm{Cav} 1.1$, later it was demonstrated that splice variations of $\operatorname{Cav} \beta_{1}$ are also expressed in the brain $\left(\operatorname{Cav} \beta_{1 b}, \operatorname{Cav} \beta_{1 c}\right.$, and $\left.\operatorname{Cav} \beta_{1 d}\right)$, particularly in cerebral cortex, habenula, hippocampus and olfactory bulb [38]. Some studies suggest association of the $C A C N B 1$ with $\mathrm{ASD}, \mathrm{BD}$ and $\mathrm{SCZ}$; however the evidence is scarce. A metanalysis of five genome-wide linkage scans in 634 affected sibling pairs found a suggestive association between the chromosome region 17p11.2-q12 and ASD, this region comprises $C A C N B 1$, however this finding requires further replication [259]. For BD, increased $C A C N B 1$ expression was reported in IPSCs derived from patients with BD relative to IPSCs from their unaffected relatives [260]. In this study, CACNAIG and CACNAIE were downregulated [260]. Regarding SCZ, only one GWAS has linked CACNB1, together with other calcium channel genes, with SCZ and working memory across multiple ages in healthy individuals [220].

\section{b) $C A C N B 2$}

$C A C N B 2$ encodes the $\operatorname{Cav} \beta_{2}$ subunit. $\operatorname{Cav} \beta_{2}$ is widely expressed in the brain, heart, and other tissues such as lung, liver and pancreas. $C A C N B 2$ has the largest number of splice variants among the $C A C N B$ genes, all these splice variants are abundant in the heart and brain [38]. $C A C N B 2$, together with $C A C N A 1 C$, is one of most consistently found risk genes for psychiatric disorders, particularly SCZ and BD. Some evidence of association of CACNB2 with MDD and ASD has also been reported. 
Several SNPs in $C A C N B 2$ have been linked to SCZ with high significance including rs7893279, rs7099380, rs17691888, rs2799573, and rs10508558. rs7893279 was identified in a Psychiatric Genomics Consortium study for SCZ [172], rs7099380 in an Ashkenazi Jew population [173], rs17691888 in a Swedish population and was further confirmed using a regulatory trait concordance approach to prioritize SNPs and genes within SCZ loci [261-263]. rs2799573 has been identified across multiple disorders including SCZ, BD, ADHD and ASD [155,264]. rs 10508558 was identified in genome-wide metanalysis for SCZ [265]. Other SNPs in CACNB2 such as rs17661538 have been linked to antipsychotic responses of clozapine [266], and rs 1277738 has been found across multiple disorders and also linked to DMN [254]. Other intronic SNPs in $C A C N B 2$ are also associated with working memory and brain activity [220].

Similar to CACNA1C, SNPs in CACNB2 have shown strong association with BD and other psychiatric disorders. In fact, the some of the SNPs in CACNB2 that are associated with BD are also associated with SCZ. For example, an association of rs11013860 with BD and SCZ was identified in a Han Chinese and Taiwanese populations [189]. A study using a pleiotropyinformed conditional false discovery rate, which improved detection of common variations associated with BD, identified rs7083127 [266]. CACNB2 has also been associated with binge eating and BD in a second study [245]. rs2489198, rs4747340, rs7083127, rs12247369, rs2799573 have been linked to the five major disorders ADHD, SCZ, ASD, BD, and MDD [155]. Furthermore, several SNPs in CACNB2 are linked to the response to SSRIs [267].

In a WES study, three variations in $C A C N B 2$ have been found in ASD probands but not in controls (G167S, S197F, and F240L), although with incomplete segregation. All three 
variations affect the kinetics of inactivation of calcium currents [268]. In a second study that included 85 family quartets (two parents and two affected siblings), the variations V2D was identified, but the functional effect of this variant is unknown [269].

c) $C A C N B 3$

$C A C N B 3$ encodes for the $\operatorname{Cav} \beta 3$ subunit and is mostly expressed in the brain and to some extent in heart, aorta, and kidney. Previous studies have shown associations of the CACNB3 with BD and SCZ. The SNPs rs2070615 and rs11168751 were found to confer risk to BD in a European population [270,271]. QLTs in CACNB3 have also been linked to both BD and ADHD [272]. Finally, pathway analysis has confirmed associations of CACNB3 with SCZ [273].

\section{d) $C A C N B 4$}

CACNB4 encodes the $\operatorname{Cav} \beta 4$ subunit, and together with $\operatorname{Cav} \beta 3$, is one of the most abundant $\operatorname{Cav} \beta$ subunits in the brain. $\operatorname{Cav} \beta 4$ subunit is the most commonly found $\operatorname{Cav} \beta$ in complex with Cav2 channels suggesting an important role of this subunit in presynaptic transmitter release [274]. Several studies have linked $C A C N B 4$ to MDD, anxiety disorders and SCZ [230,261,275].

\section{Cav modulators for the treatment of psychiatric disorders}


Given the large amount of evidence from multiple studies implicating Cav genes in the pathophysiology of psychiatry disorders, it is worthwhile to consider targeting $\operatorname{Cav} \alpha_{1}, \operatorname{Cav} \alpha_{2} \delta$, and $\operatorname{Cav} \beta$ subunits as a potential therapeutic strategy to treat these disorders. Although several drugs targeting $\operatorname{Cav} \alpha_{1}, \operatorname{Cav} \alpha_{2} \delta$, and $\operatorname{Cav} \beta$ subunits already exist, they are typically prescribed to treat cardiovascular conditions, pain, and epilepsy [17]. However, drugs with anti-epileptic and analgesic effects such as gabapentin and pregabalin are now being explored as a novel approach to treat anxiety [276]. Similarly, topiramate, a drug that has several targets including Cav2.2 and Cav2.3 channels, has shown some promise to treat posttraumatic stress disorder (PTSD) comorbid with alcohol dependence [277]. Cav2.2 channel blockers such as Z160 and CNV2197944 are being considered to treat anxiety (Table 2) [17].

Currently several trials targeting Cavs and auxiliary subunits have been completed or are being performed (www.clinicaltrials.gov). The L-type channel blockers, nimodipine and isradipine are being evaluated on cognitive performance in patients with SCZ. Ethosuximide, a drug that blocks Cav3 channels, is being tested for treatment-resistant depression. Gabapentin is also being tested for bipolar disorder. In recent years there has been over 35 clinical trials completed testing the efficacy of lamotrigine (a drug that targets Cav2.3 channels [278,279] ) in bipolar disorder as well as clinical trials for major depression and schizophrenia. Drugs targeting Cavs that are showing promise in animal models are the Cav3 channel enhancer, Sak3. This drug has been found to reduce depressive-like behaviors in mice by increasing serotonin and dopamine levels (Table 2) [280,281].

\section{Conclusions}


Modern analysis of large cohorts has shed tremendous amount of light on the genetic risks associated with psychiatric disorders. Techniques such as next generation sequencing, microarrays, linkage studies, endophenotype analysis and computer modeling are increasing our chances to elucidate the cellular and molecular mechanisms underlying psychiatry disorders. Although most genetic studies strongly suggest that multiple genes are associated with psychiatric disorders, risk variations in $\mathrm{Ca}_{\mathrm{v}}$ gene have been consistently found associated with the five major psychiatric disorders SCZ, MDD, ADHD, ASD, and BD. This nicely aligns with the neuronal functions of Cav genes.

The $\operatorname{Cav} \alpha_{1}, \operatorname{Cav} \alpha_{2} \delta$, and $\operatorname{Cav} \beta$ subunits are relatively well-known pharmacological targets. Several studies have demonstrated their involvement in neuronal firing, axon guidance, neuronal development, synapse formation and activity-dependent function. However, a major challenge is to link risk variations of $\mathrm{Cav}$ genes to their pathophysiological functions in the context of psychiatric disorders. Studies on the SNP rs1006737 in CACNA1C are leading the way on this, several studies been performed at the molecular, cellular and behavioral level to elucidate how this risk variation is involved in BD. However, in addition to individual risk variations, it is important to weigh the compounded effect of individual variations as they interact with other genes, and with the environment. Machine learning is becoming a novel approach to integrate information arising from genetic studies to elucidate the various mechanisms that are likely to underlie psychiatric disorders, as shown with PsychEncode. 
For therapeutic purposes, tissue expression of $\mathrm{Cav}$ genes should be taken into account. For example, Cav1.2 channels are promising targets for BD and SCZ, however their robust expression in the heart and blood vessels poses a challenge for intervention. Further studies should aim at blocking or activating specific Cavs present in the brain but not in the heart. Alternative splicing is a possible path for drug specificity, because Cav1.2 splice variants in the heart are substantially different from the ones in the brain [22]. Nonetheless, Cavs offer an intriguing viable option to develop novel treatments for psychiatric disorders.

\section{ACKNOWLEDGEMENTS}

R00MH099405 (AA)

AUTHOR CONTRIBUTIONS. All authors contributed to literature search. AB, SM and AA wrote the manuscript.

CONFLICTS OF INTEREST. Authors declare no conflict of interest.

\section{FIGURE LEGENDS}

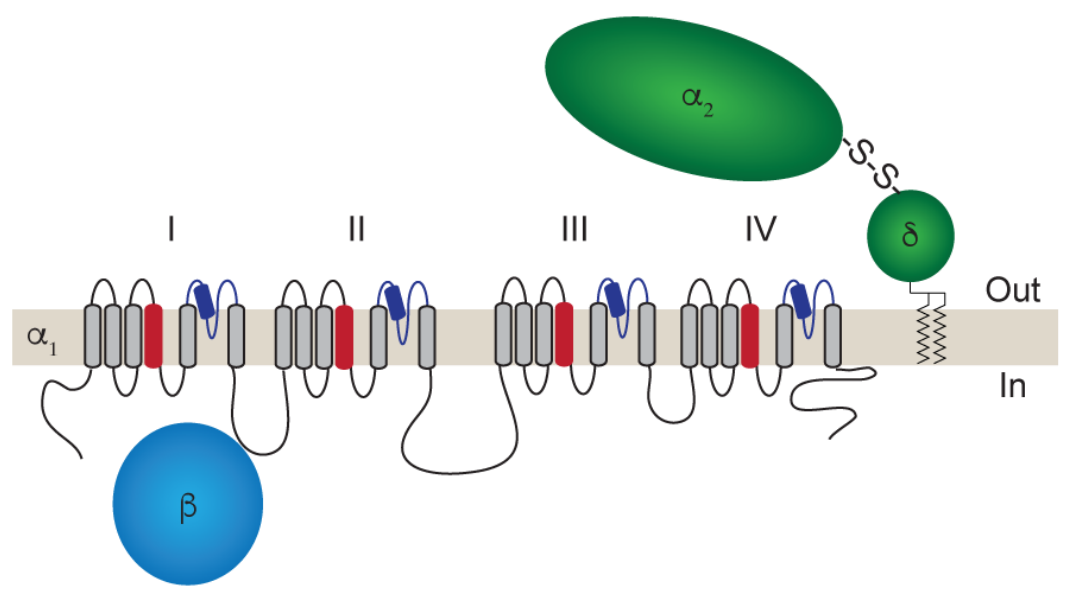


Figure 1. Schematic representation of a $\operatorname{Cav}$ complex. The $\operatorname{Cav} \alpha_{1}, \operatorname{Cav} \alpha_{2} \delta$, and $\operatorname{Cav} \beta$ subunits are depicted. The 24 transmembrane segments of the Cavo $\alpha_{1}$ subunit are shown arranged in the four domains (D1-IV), the voltage sensors are indicated in red, and the reentrant loop between S5 and S6 (P-loop) in dark blue. The GPI-anchored $\mathrm{Cav}_{2} \alpha_{2} \delta$ is shown in green, and the cytoplasmic $\operatorname{Cav} \beta$ subunit in light blue.

Table 1. Nomenclature and classification of $\mathrm{Cav} \alpha_{1}$ subunits based on sequence similarity and biophysical properties.

\begin{tabular}{|c|c|c|c|c|c|}
\hline $\begin{array}{c}\text { Gene name } \\
\text { in human }\end{array}$ & $\begin{array}{c}\begin{array}{c}\text { Protein name } \\
\text { (old) }\end{array} \\
\end{array}$ & $\begin{array}{c}\begin{array}{c}\text { Protein name } \\
\text { (new) }\end{array} \\
\end{array}$ & $\begin{array}{c}\text { Current } \\
\text { type }\end{array}$ & Subfamily & $\begin{array}{c}\text { Threshold of } \\
\text { activation }\end{array}$ \\
\hline CACNAIS & $\alpha_{1 \mathrm{~S}}$ & $\mathrm{Ca}_{\mathrm{v}} 1.1$ & $\mathrm{~L}$ & \multirow{4}{*}{ Cav1 } & \multirow{7}{*}{$\begin{array}{c}\text { HVA } \\
\text { (associated with } \\
\operatorname{Cav} \alpha_{2} \delta \text { and } \operatorname{Cav} \beta \\
\text { subunits) }\end{array}$} \\
\hline CACNAIC & $\alpha_{1 C}$ & $\mathrm{Ca}_{\mathrm{v}} 1.2$ & $\mathrm{~L}$ & & \\
\hline CACNA1D & $\alpha_{1 \mathrm{D}}$ & $\mathrm{Ca}_{\mathrm{v}} 1.3$ & $\mathrm{~L}$ & & \\
\hline CACNA1F & $\alpha_{1 \mathrm{~F}}$ & $\mathrm{Ca}_{\mathrm{v}} 1.4$ & $\mathrm{~L}$ & & \\
\hline CACNAIA & $\alpha_{1 \mathrm{~A}}$ & $\mathrm{Ca}_{v} 2.1$ & $\mathrm{P} / \mathrm{Q}$ & \multirow{3}{*}{$\mathrm{Cav} 2$} & \\
\hline$C A C N A 1 B$ & $\alpha_{1 \mathrm{~B}}$ & $\mathrm{Ca}_{\mathrm{v}} 2.2$ & $\mathrm{~N}$ & & \\
\hline CACNAIE & $\alpha_{1 \mathrm{E}}$ & $\mathrm{Ca}_{\mathrm{v}} 2.3$ & $\mathrm{R}$ & & \\
\hline CACNA1G & $\alpha_{1 \mathrm{G}}$ & $\mathrm{Ca}_{\mathrm{v}} 3.1$ & $\mathrm{~T}$ & \multirow{3}{*}{ Cav3 } & \multirow{3}{*}{$\begin{array}{c}\text { LVA } \\
\text { (associated with } \\
\text { CACHD1) }\end{array}$} \\
\hline CACNA1H & $\alpha_{1 \mathrm{H}}$ & $\mathrm{Ca}_{\mathrm{v}} 3.2$ & $\mathrm{~T}$ & & \\
\hline CACNAII & $\alpha_{1 I}$ & $\mathrm{Ca}_{\mathrm{v}} 3.3$ & $\mathrm{~T}$ & & \\
\hline
\end{tabular}

Table 2. Summary of genetic links between Cav genes and psychiatric disorders, classical modulators of Cavs, and their potential use to treat psychiatric disorders

\begin{tabular}{|c|c|c|c|}
\hline $\begin{array}{c}\text { Gene name in } \\
\text { human }\end{array}$ & Associated Disorder & $\begin{array}{c}\text { Classical } \\
\text { modulators }\end{array}$ & $\begin{array}{c}\text { Potential therapeutic } \\
\text { intervention for psychiatric } \\
\text { disorders }\end{array}$ \\
\hline$C A C N A 1 S$ & --- & & $\begin{array}{l}\bullet \text { Nimodipine }(\mathrm{SCZ}) \\
\bullet \text { Isradipine (BD, SCZ) }\end{array}$ \\
\hline$C A C N A 1 C$ & $\begin{array}{c}\mathrm{ASD}, \mathrm{SCZ}, \mathrm{BD}, \\
\mathrm{MDD}, \mathrm{ADHD}\end{array}$ & Dihydropyridines & \\
\hline
\end{tabular}




\begin{tabular}{|c|c|c|c|}
\hline CACNA1D & $\begin{array}{l}\text { ASD, SCZ, BD, } \\
\text { MDD, ADHD }\end{array}$ & & \multirow[t]{2}{*}{$\begin{array}{l}\text { - Verapamil (BD) } \\
\text { - Diltiazem (BD) }\end{array}$} \\
\hline CACNAIF & --- & & \\
\hline CACNAIA & SCZ, ADHD, MDD & $\omega$-Agatoxin IVA & TBD \\
\hline CACNAIB & SCZ, ASD, MDD & $\omega$-Conotoxin GVIA & $\begin{array}{l}\text { - CNV2197944 (anxiety) } \\
\text { - Z160 (anxiety) }\end{array}$ \\
\hline CACNAIE & ASD, MDD, SCZ & SNX 482 & $\begin{array}{l}\text { - Lamotrigine (BD, SCZ, } \\
\text { treatment resistant } \\
\text { depression, anxiety) } \\
\text { - Topiramate (PTSD) }\end{array}$ \\
\hline CACNAIG & ASD & \multirow{3}{*}{$\begin{array}{l}\text { TTA-A2, TTA-P2, } \\
\text { ProTx-I, ProTx-II }\end{array}$} & \multirow[t]{3}{*}{ - Sak3 (MDD) } \\
\hline CACNAIH & ASD, SCZ & & \\
\hline CACNAII & SCZ, ADHD, ASD & & \\
\hline CACNA2D1 & $\mathrm{MDD}, \mathrm{BD}, \mathrm{SCZ}$ & \multirow{2}{*}{$\begin{array}{c}\text { Gabapentin, } \\
\text { pregabalin }\end{array}$} & \multirow{2}{*}{$\begin{array}{l}\text { - Pregabalin (anxiety, SCZ) } \\
\text { - Gabapentin (anxiety, mood } \\
\text { disorders) }\end{array}$} \\
\hline CACNA2D2 & SCZ & & \\
\hline CACNA2D3 & ASD, SCZ, BD & \multirow[t]{2}{*}{ TBD } & \multirow[t]{2}{*}{ TBD } \\
\hline CACNA2D4 & $\begin{array}{l}\text { ASD, SCZ, BD, } \\
\text { MDD, ADHD }\end{array}$ & & \\
\hline$C A C N B 1$ & $\mathrm{ASD}, \mathrm{BD}, \mathrm{SCZ}$ & \multirow[t]{4}{*}{ TBD } & \multirow[t]{4}{*}{ TBD } \\
\hline CACNB2 & $\begin{array}{l}\text { ASD, SCZ, BD, } \\
\text { MDD, ADHD }\end{array}$ & & \\
\hline$C A C N B 3$ & ASD, BD, SCZ & & \\
\hline CACNB4 & $\begin{array}{l}\text { MDD, SCZ, anxiety } \\
\text { disorders }\end{array}$ & & \\
\hline
\end{tabular}

\section{REFERENCES}

1. Nanou, E.; Catterall, W.A. Calcium Channels, Synaptic Plasticity, and Neuropsychiatric Disease. Neuron 2018, 98, 466-481.

2. Felix, R.; Calderón-Rivera, A.; Andrade, A. Regulation of high-voltage-activated Ca2+ channel function, trafficking, and membrane stability by auxiliary subunits. Wiley Interdiscip Rev Membr Transp Signal 2013, 2, 207-220. 
3. Dolphin, A.C. Calcium channel diversity: multiple roles of calcium channel subunits. Current Opinion in Neurobiology 2009, 19, 237-244.

4. Fletcher, C.F.; Lutz, C.M.; O’Sullivan, T.N.; Shaughnessy, J.D.; Hawkes, R.; Frankel, W.N.; Copeland, N.G.; Jenkins, N.A. Absence Epilepsy in Tottering Mutant Mice Is Associated with Calcium Channel Defects. Cell 1996, 87, 607-617.

5. Lorenzon, N.M.; Lutz, C.M.; Frankel, W.N.; Beam, K.G. Altered Calcium Channel Currents in Purkinje Cells of the Neurological Mutant Mouse leaner. J Neurosci 1998, 18, 4482-4489.

6. Barclay, J.; Balaguero, N.; Mione, M.; Ackerman, S.L.; Letts, V.A.; Brodbeck, J.; Canti, C.; Meir, A.; Page, K.M.; Kusumi, K.; et al. Ducky Mouse Phenotype of Epilepsy and Ataxia Is Associated with Mutations in the Cacna2d2 Gene and Decreased Calcium Channel Current in Cerebellar Purkinje Cells. J Neurosci 2001, 21, 6095-6104.

7. Zhang, Z.; Xu, Y.; Song, H.; Rodriguez, J.; Tuteja, D.; Namkung, Y.; Shin, H.-S.; Chiamvimonvat, N. Functional Roles of Cav1.3 ( $\alpha$ 1D) Calcium Channel in Sinoatrial Nodes. Circ Res 2002, 90, 981-987.

8. Kim, C.; Jun, K.; Lee, T.; Kim, S.-S.; McEnery, M.W.; Chin, H.; Kim, H.-L.; Park, J.; Kim, D.; Jung, S.; et al. Altered Nociceptive Response in Mice Deficient in the $\alpha 1 \mathrm{~B}$ Subunit of the Voltage-Dependent Calcium Channel. Mol Cell Neurosci 2001, 18, 235-245. 
9. Saegusa, H.; Kurihara, T.; Zong, S.; Kazuno, A.; Matsuda, Y.; Nonaka, T.; Han, W.;

Toriyama, H.; Tanabe, T. Suppression of inflammatory and neuropathic pain symptoms in mice lacking the N-type Ca2+ channel. The EMBO Journal 2001, 20, 2349-56.

10. Burgess, D.L.; Jones, J.M.; Meisler, M.H.; Noebels, J.L. Mutation of the Ca2+ Channel $\beta$ Subunit Gene Cchb4 Is Associated with Ataxia and Seizures in the Lethargic (lh) Mouse. Cell 1997, 88, 385-392.

11. Rajakulendran, S.; Hanna, M.G. The Role of Calcium Channels in Epilepsy. Csh Perspect Med 2016, 6, a022723.

12. Surmeier, J.D. Calcium, ageing, and neuronal vulnerability in Parkinson's disease. Lancet Neurology 2007, 6, 933-938.

13. Celli, R.; Santolini, I.; Guiducci, M.; van Luijtelaar, G.; Parisi, P.; Striano, P.; Gradini, R.; Battaglia, G.; Ngomba, R.T.; Nicoletti, F. The A2 $\delta$ Subunit and Absence Epilepsy: Beyond Calcium Channels? Curr Neuropharmacol 2017, 15, 1-1.

14. Pietrobon, D. Ion channels in migraine disorders. Curr Opin Physiology 2018.

15. Striessnig, J. Voltage-gated calcium channels - from basic mechanisms to disease. $J$ Physiology 2016, 594, 5817-5821. 
16. Bourinet, E.; Francois, A.; Laffray, S. T-type calcium channels in neuropathic pain. Pain 2016, 157, S15-S22.

17. Zamponi, G.W. Targeting voltage-gated calcium channels in neurological and psychiatric diseases. Nat Rev Drug Discov 2015, 15, 19-34.

18. Heyes, S.; Pratt, W.S.; Rees, E.; Dahimene, S.; Ferron, L.; Owen, M.J.; Dolphin, A.C. Genetic disruption of voltage-gated calcium channels in psychiatric and neurological disorders. Prog Neurobiol 2015, 134, 36-54.

19. Catterall, W.A.; Perez-Reyes, E.; Snutch, T.P.; Striessnig, J. International Union of Pharmacology. XLVIII. Nomenclature and Structure-Function Relationships of Voltage-Gated Calcium Channels. Pharmacol Rev 2005, 57, 411-425.

20. Perez-Reyes, E. Molecular Physiology of Low-Voltage-Activated T-type Calcium Channels. Physiological Reviews 2003, 83, 117-161.

21. Xu, W.; Lipscombe, D. Neuronal CaV1.3 $\alpha 1$ L-Type Channels Activate at Relatively Hyperpolarized Membrane Potentials and Are Incompletely Inhibited by Dihydropyridines. Journal of Neuroscience 2001, 21, 5944-5951.

22. Lipscombe, D.; Andrade, A. Calcium Channel CaV $\alpha_{1}$ Splice Isoforms - Tissue Specificity 
and Drug Action. Current molecular pharmacology 2015, 8, 22-31.

23. Lipscombe, D.; Andrade, A.; Allen, S.E. Alternative splicing: Functional diversity among voltage-gated calcium channels and behavioral consequences. Biochimica et Biophysica Acta (BBA) - Biomembranes 2013, 1828, 1522-1529.

24. Catterall, W.A. Voltage-Gated Calcium Channels. Cold Spring Harbor Perspectives in Biology 2011, 3, a003947.

25. Calderón-Rivera, A.; Andrade, A.; Hernández-Hernández, O.; González-Ramírez, R.; Sandoval, A.; Rivera, M.; Gomora, J.; Felix, R. Identification of a disulfide bridge essential for structure and function of the voltage-gated $\mathrm{Ca} 2+$ channel $\alpha 2 \delta-1$ auxiliary subunit. Cell Calcium 2012, 51, 22-30.

26. Jongh, D.K.; Warner, C.; Catterall, W. Subunits of purified calcium channels. Alpha 2 and delta are encoded by the same gene. The Journal of biological chemistry 1990, 265, 14738-41.

27. Davies, A.; Kadurin, I.; Alvarez-Laviada, A.; Douglas, L.; Nieto-Rostro, M.; Bauer, C.S.; Pratt, W.S.; Dolphin, A.C. The $\alpha 2 \delta$ subunits of voltage-gated calcium channels form GPIanchored proteins, a posttranslational modification essential for function. Proc National Acad Sci 2010, 107, 1654-1659.

28. Anantharaman, V.; Aravind, L. Cache - a signaling domain common to animal Ca2+-channel 
subunits and a class of prokaryotic chemotaxis receptors. Trends Biochem Sci 2000, 25, 535537.

29. Cantí, C.; Nieto-Rostro, M.; Foucault, I.; Heblich, F.; Wratten, J.; Richards, M.; Hendrich, J.;

Douglas, L.; Page, K.; Davies, A.; et al. The metal-ion-dependent adhesion site in the Von Willebrand factor-A domain of $\alpha 2 \delta$ subunits is key to trafficking voltage-gated Ca2+ channels. Proceedings of the National Academy of Sciences of the United States of America 2005, 102, $11230-11235$.

30. Dolphin, A.C. Voltage-gated calcium channel $\alpha 2 \delta$ subunits: an assessment of proposed novel roles. F1000Research 2018, 7, F1000 Faculty Rev-1830.

31. Dolphin, A.C. The $\alpha 2 \delta$ subunits of voltage-gated calcium channels. Biochimica Et Biophysica Acta Bba - Biomembr 2013, 1828, 1541-1549.

32. Patel, R.; Dickenson, A.H. Mechanisms of the gabapentinoids and $\alpha 2 \delta-1$ calcium channel subunit in neuropathic pain. Pharmacol Res Perspectives 2016, 4, e00205.

33. Angelotti, T.; Hofmann, F. Tissue-specific expression of splice variants of the mouse voltage-gated calcium channel $\alpha 2 / \delta$ subunit. Febs Lett 1996, 397, 331-337.

34. Lana, B.; Schlick, B.; Martin, S.; Pratt, W.S.; Page, K.M.; Goncalves, L.; Rahman, W.; Dickenson, A.H.; Bauer, C.S.; Dolphin, A.C. Differential upregulation in DRG neurons of an 
$\alpha 2 \delta$-1 splice variant with a lower affinity for gabapentin after peripheral sensory nerve injury.

Pain 2014, 155, 522-533.

35. Neely, A.; Hidalgo, P. Structure-function of proteins interacting with the $\alpha 1$ pore-forming subunit of high-voltage-activated calcium channels. Front Physiol 2014, 5, 209.

36. Chien, A.J.; Carr, K.M.; Shirokov, R.E.; Rios, E.; Hosey, M.M. Identification of Palmitoylation Sites within the L-type Calcium Channel $\beta 2$ a Subunit and Effects on Channel Function. Journal of Biological Chemistry 1996, 271, 26465-26468.

37. Subramanyam, P.; Obermair, G.J.; Baumgartner, S.; Gebhart, M.; Striessnig, J.; Kaufmann, W.A.; Geley, S.; Flucher, B.E. Activity and calcium regulate nuclear targeting of the calcium channel beta4b subunit in nerve and muscle cells. Channels (Austin, Tex.) 2009, 3, 343-55.

38. Zhang, Y.; Yamada, Y.; Fan, M.; Bangaru, S.D.; Lin, B.; Yang, J. The $\beta$ Subunit of Voltagegated Ca2+ Channels Interacts with and Regulates the Activity of a Novel Isoform of Pax6. $J$ Biol Chem 2010, 285, 2527-2536.

39. Xu, X.; Lee, Y.J.; Holm, J.B.; Terry, M.D.; Oswald, R.E.; Horne, W.A. The Ca2+ Channel $\beta 4 \mathrm{c}$ Subunit Interacts with Heterochromatin Protein 1 via a PXVXL Binding Motif. Journal of Biological Chemistry 2011, 286, 9677-9687.

40. He, L.; Zhang, Y.; Chen, Y.; Yamada, Y.; Yang, J. Functional Modularity of the $\beta$-Subunit of 
Voltage-Gated Ca2+ Channels. Biophys J 2007, 93, 834-845.

41. McGee, A.W.; Nunziato, D.A.; Maltez, J.M.; Prehoda, K.E.; Pitt, G.S.; Bredt, D.S. Calcium Channel Function Regulated by the SH3-GK Module in $\beta$ Subunits. Neuron 2004, 42, 89-99.

42. Chen, Y.; Li, M.; Zhang, Y.; He, L.; Yamada, Y.; Fitzmaurice, A.; Shen, Y.; Zhang, H.; Tong, L.; Yang, J. Structural basis of the $\alpha 1-\beta$ subunit interaction of voltage-gated Ca2+ channels. Nature 2004, 429, 675.

43. Petegem, F.; Clark, K.A.; Chatelain, F.C.; Jr, D.L. Structure of a complex between a voltagegated calcium channel $\beta$-subunit and an $\alpha$-subunit domain. Nature 2004, 429, 671.

44. Gonzalez-Gutierrez, G.; Miranda-Laferte, E.; Neely, A.; Hidalgo, P. The Src Homology 3 Domain of the $\beta$-Subunit of Voltage-gated Calcium Channels Promotes Endocytosis via Dynamin Interaction. Journal of Biological Chemistry 2007, 282, 2156-2162.

45. Wu, J.; Yan, Z.; Li, Z.; Yan, C.; Lu, S.; Dong, M.; Yan, N. Structure of the voltage-gated calcium channel Cav1.1 complex. Science 2015, 350, aad2395.

46. Mears, D. Regulation of Insulin Secretion in Islets of Langerhans by Ca2+Channels. $J$ Membr Biology 2004, 200, 57-66.

47. Wheeler, D.G.; Groth, R.D.; Ma, H.; Barrett, C.F.; Owen, S.F.; Safa, P.; Tsien, R.W. CaV1 
and CaV2 Channels Engage Distinct Modes of Ca2+ Signaling to Control CREB-Dependent Gene Expression. Cell 2012, 149, 1112-1124.

48. Moreno, C.M.; Dixon, R.E.; Tajada, S.; Yuan, C.; Opitz-Araya, X.; Binder, M.D.; Santana, L.F. Ca2+ entry into neurons is facilitated by cooperative gating of clustered CaV1.3 channels. Elife 2016, 5, e15744.

49. Li, B.; Tadross, M.R.; Tsien, R.W. Sequential ionic and conformational signaling by calcium channels drives neuronal gene expression. Science 2016, 351, 863-867.

50. Shi, L.; Chang, J.; Yu, F.; Ko, M.L.; Ko, G. The Contribution of L-Type Cav1.3 Channels to Retinal Light Responses. Front Mol Neurosci 2017, 10, 394.

51. Comunanza, V.; Marcantoni, A.; Vandael, D.H.; Mahapatra, S.; Gavello, D.; Carabelli, V.; Carbone, E. CaV1.3 as pacemaker channels in adrenal chromaffin cells: specific role on exo- and endocytosis? Channels (Austin, Tex.) 2010, 4, 440-6.

52. Liu, Y.; Harding, M.; Pittman, A.; Dore, J.; Striessnig, J.; Rajadhyaksha, A.; Chen, X. Cav1.2 and Cav1.3 L-type calcium channels regulate dopaminergic firing activity in the mouse ventral tegmental area. Journal of Neurophysiology 2014, 112, 1119-1130.

53. Vandael, D.H.; Marcantoni, A.; Carbone, E. Cav1.3 Channels as Key Regulators of NeuronLike Firings and Catecholamine Release in Chromaffin Cells. Current molecular pharmacology 
2015, 8, 149-61.

54. Surmeier, J.D.; Schumacker, P.T.; Guzman, J.D.; Ilijic, E.; Yang, B.; Zampese, E. Calcium and Parkinson's disease. Biochem Bioph Res Co 2017, 483, 1013-1019.

55. Brandt, A.; Striessnig, J.; Moser, T. CaV1.3 Channels Are Essential for Development and Presynaptic Activity of Cochlear Inner Hair Cells. J Neurosci 2003, 23, 10832-10840.

56. Mangoni, M.E.; Couette, B.; Bourinet, E.; Platzer, J.; Reimer, D.; Striessnig, J.; Nargeot, J. Functional role of L-type Cav1.3 Ca2+ channels in cardiac pacemaker activity. Proceedings of the National Academy of Sciences 2003, 100, 5543-5548.

57. Torrente, A.; Mesirca, P.; Neco, P.; Rizzetto, R.; Dubel, S.; Barrere, C.; Sinegger-Brauns, M.; Striessnig, J.; Richard, S.; Nargeot, J.; et al. L-type Cav1.3 channels regulate ryanodine receptor-dependent $\mathrm{Ca} 2+$ release during sino-atrial node pacemaker activity. Cardiovascular Research 2016, 109, 451-461.

58. Lee, A.; Wang, S.; Williams, B.; Hagen, J.; Scheetz, T.E.; Haeseleer, F. Characterization of Cav1.4 Complexes $(\alpha 11.4, \beta 2$, and $\alpha 2 \delta 4)$ in HEK293T Cells and in the Retina. Journal of Biological Chemistry 2015, 290, 1505-1521.

59. Waldner, D.; Bech-Hansen, N.; Stell, W. Channeling Vision: CaV1.4-A Critical Link in Retinal Signal Transmission. BioMed Research International 2018, 2018, 1-14. 
60. Stanley, E.F. PresyNaptic Calcium Channels: Why Is P Selected before N? Biophysical Journal 2015, 108, 451-452.

61. Stanley, E.F. The Nanophysiology of Fast Transmitter Release. Trends Neurosci 2016, 39, 183-197.

62. Beuckmann, C.T.; nton, C.; Miyamoto, N.; Ino, M.; Yanagisawa, M. N-Type Calcium Channel $\alpha 1 B$ Subunit (CaV2.2) Knock-Out Mice Display Hyperactivity and Vigilance State Differences. Journal of Neuroscience 2003, 23, 6793-6797.

63. Kim, C.; Jeon, D.; Kim, Y.-H.; Lee, J.C.; Kim, H.; Shin, H.-S. Deletion of N-type Ca2+ Channel Cav2.2 Results in Hyperaggressive Behaviors in Mice. J Biol Chem 2009, 284, 27382745 .

64. Brimblecombe, K.R.; Gracie, C.J.; Platt, N.J.; Cragg, S.J. Gating of dopamine transmission by calcium and axonal N-, Q-, T- and L-type voltage-gated calcium channels differs between striatal domains. The Journal of Physiology 2015, 593, 929-946.

65. Lenkey, N.; Kirizs, T.; Holderith, N.; Máté, Z.; Szabó, G.; Vizi, S.E.; Hájos, N.; Nusser, Z. Tonic endocannabinoid-mediated modulation of GABA release is independent of the CB1 content of axon terminals. Nature Communications 2015, 6, 6557. 
66. Szabó, G.G.; Lenkey, N.; Holderith, N.; Andrási, T.; Nusser, Z.; Hájos, N. Presynaptic Calcium Channel Inhibition Underlies CB1 Cannabinoid Receptor-Mediated Suppression of GABA Release. The Journal of Neuroscience 2014, 34, 7958-63.

67. Parajuli, L.; Nakajima, C.; Kulik, A.; Matsui, K.; Schneider, T.; Shigemoto, R.; Fukazawa, Y. Quantitative Regional and Ultrastructural Localization of the Cav2.3 Subunit of R-type Calcium Channel in Mouse Brain. The Journal of Neuroscience 2012, 32, 13555-13567.

68. Kamp, M.; Krieger, A.; Henry, M.; Hescheler, J.; Weiergräber, M.; Schneider, T. Presynaptic ‘Cav2.3-containing' E-type Ca2+ channels share dual roles during neurotransmitter release. Eur J Neurosci 2005, 21, 1617-1625.

69. Bloodgood, B.L.; Sabatini, B.L. Nonlinear Regulation of Unitary Synaptic Signals by CaV2.3 Voltage-Sensitive Calcium Channels Located in Dendritic Spines. Neuron 2007, 53, 249-260.

70. Zamponi, G.W.; Currie, K. Regulation of CaV2 calcium channels by G protein coupled receptors. Biochimica et Biophysica Acta (BBA) - Biomembranes 2013, 1828, 1629-1643.

71. Juliane; Weiss, N. G Protein Regulation of Neuronal Calcium Channels: Back to the Future. Mol Pharmacol 2015, 87, 890-906.

72. He, R.; Zhang, J.; Yu, Y.; Jizi, L.; Wang, W.; Li, M. New Insights Into Interactions of 
Presynaptic Calcium Channel Subtypes and SNARE Proteins in Neurotransmitter Release. Frontiers in Molecular Neuroscience 2018, 11, 213.

73. Zamponi, G.W.; Striessnig, J.; Koschak, A.; Dolphin, A.C. The Physiology, Pathology, and Pharmacology of Voltage-Gated Calcium Channels and Their Future Therapeutic Potential. Pharmacol Rev 2015, 67, 821-870.

74. Lambert, R.C.; Bessaïh, T.; Crunelli, V.; Leresche, N. The many faces of T-type calcium channels. Pflügers Archiv - European Journal of Physiology 2014, 466, 415-423.

75. Vassort, G.; Talavera, K.; Alvarez, J.L. Role of T-type Ca2+ channels in the heart. Cell Calcium 2006, 40, 205-220.

76. Mesirca, P.; Torrente, A.G.; Mangoni, M.E. T-type channels in the sino-atrial and atrioventricular pacemaker mechanism. Pflügers Archiv - European Journal of Physiology 2014, $466,791-799$.

77. Suzuki, S.; Rogawski, M. T-type calcium channels mediate the transition between tonic and phasic firing in thalamic neurons. Proceedings of the National Academy of Sciences 1989, 86, $7228-7232$.

78. Campiglio, M.; Flucher, B.E. The Role of Auxiliary Subunits for the Functional Diversity of Voltage-Gated Calcium Channels. J Cell Physiol 2015, 230, 2019-2031. 
79. Dolphin, A.C. Voltage-gated calcium channels and their auxiliary subunits: physiology and pathophysiology and pharmacology. The Journal of Physiology 2016, 594, 5369-5390.

80. Cottrell, G.S.; Soubrane, C.H.; Hounshell, J.A.; Lin, H.; Owenson, V.; Rigby, M.; Cox, P.J.; Barker, B.S.; Ottolini, M.; Ince, S.; et al. CACHD1 is an $\alpha 2 \delta$-Like Protein That Modulates CaV3 Voltage-Gated Calcium Channel Activity. The Journal of Neuroscience 2018, 38, 9186-9201.

81. Neely, G.G.; Hess, A.; Costigan, M.; Keene, A.C.; Goulas, S.; Langeslag, M.; Griffin, R.S.; Belfer, I.; Dai, F.; Smith, S.B.; et al. A Genome-wide Drosophila Screen for Heat Nociception Identifies $\alpha 2 \delta 3$ as an Evolutionarily Conserved Pain Gene. Cell 2010, 143, 628-638.

82. Geisler, S.; Schöpf, C.L.; Obermair, G.J. Emerging evidence for specific neuronal functions of auxiliary calcium channel $\alpha 2 \delta$ subunits. General physiology and biophysics 2015, 34, 105118.

83. Müller, L.; Liu, J.; Solomon, A.; Rodriguez, A.; Brecha, N.C. Expression of voltage-gated calcium channel $\alpha 2 \delta 4$ subunits in the mouse and rat retina. J Comp Neurol 2013, 521, 24862501.

84. Eroglu, Ç.; Allen, N.J.; Susman, M.W.; O’Rourke, N.A.; Park, C.; Özkan, E.; Chakraborty, C.; Mulinyawe, S.B.; Annis, D.S.; Huberman, A.D.; et al. Gabapentin Receptor $\alpha 2 \delta$-1 Is a Neuronal Thrombospondin Receptor Responsible for Excitatory CNS Synaptogenesis. Cell 
2009, 139, 380-392.

85. Tong, X.-J.J.; López-Soto, E.J.; Li, L.; Liu, H.; Nedelcu, D.; Lipscombe, D.; Hu, Z.; Kaplan, J.M. Retrograde Synaptic Inhibition Is Mediated by $\alpha$-Neurexin Binding to the $\alpha 2 \delta$ Subunits of N-Type Calcium Channels. Neuron 2017, 95, 326-340.e5.

86. Brockhaus, J.; Schreitmüller, M.; Repetto, D.; Klatt, O.; Reissner, C.; Elmslie, K.; Heine, M.; Missler, M. $\alpha$-Neurexins Together with $\alpha 2 \delta$-1 Auxiliary Subunits Regulate Ca2+ Influx through Cav2.1 Channels. The Journal of neuroscience : the official journal of the Society for Neuroscience 2018, 38, 8277-8294.

87. Chen, J.; Li, L.; Chen, S.-R.R.; Chen, H.; Xie, J.-D.D.; Sirrieh, R.E.; MacLean, D.M.; Zhang, Y.; Zhou, M.-H.H.; Jayaraman, V.; et al. The $\alpha 2 \delta-1-N M D A$ Receptor Complex Is Critically Involved in Neuropathic Pain Development and Gabapentin Therapeutic Actions. Cell reports 2018, 22, 2307-2321.

88. Bichet, D.; Cornet, V.; Geib, S.; Carlier, E.; Volsen, S.; Hoshi, T.; Mori, Y.; Waard, M. The I-II Loop of the Ca2+ Channel $\alpha 1$ Subunit Contains an Endoplasmic Reticulum Retention Signal Antagonized by the $\beta$ Subunit. Neuron 2000, 25, 177-190.

89. Zou, S.; Jha, S.; Kim, E.; Dryer, S.E. The $\beta 1$ Subunit of L-Type Voltage-Gated Ca2+ Channels Independently Binds to and Inhibits the Gating of Large-Conductance Ca2+-Activated K+ Channels. Molecular Pharmacology 2008, 73, 369-378. 
90. Zhuchenko, O.; Bailey, J.; Bonnen, P.; Ashizawa, T.; Stockton, D.W.; Amos, C.; Dobyns, W.B.; Subramony, S.H.; Zoghbi, H.Y.; Lee, C. Autosomal dominant cerebellar ataxia (SCA6) associated with small polyglutamine expansions in the $\alpha 1 \mathrm{~A}$-voltage-dependent calcium channel. Nat Genet 1997, 15, 62-69.

91. Splawski, I.; Timothy, K.W.; Sharpe, L.M.; Decher, N.; Kumar, P.; Bloise, R.; Napolitano, C.; Schwartz, P.J.; Joseph, R.M.; Condouris, K.; et al. CaV1.2 Calcium Channel Dysfunction Causes a Multisystem Disorder Including Arrhythmia and Autism. Cell 2004, 119, 19-31.

92. Yabe, I.; Sasaki, H.; Matsuura, T.; Takada, A.; Wakisaka; Suzuki, Y.; Fukazawa, T.; Hamada, T.; Oda, T.; Ohnishi, A.; et al. SCA6 mutation analysis in a large cohort of the Japanese patients with late-onset pure cerebellar ataxia. J Neurol Sci 1998, 156, 89-95.

93. Giunti, P.; Mantuano, E.; Frontali, M.; Veneziano, L. Molecular mechanism of Spinocerebellar Ataxia type 6: glutamine repeat disorder, channelopathy and transcriptional dysregulation. The multifaceted aspects of a single mutation. Front Cell Neurosci 2015, 9, 36.

94. Fukuyama, M.; Wang, Q.; Kato, K.; Ohno, S.; Ding, W.-G.; Toyoda, F.; Itoh, H.; Kimura, H.; Makiyama, T.; Ito, M.; et al. Long QT syndrome type 8: novel CACNA1C mutations causing QT prolongation and variant phenotypes. Ep Europace 2014, 16, 1828-1837.

95. Wemhöner, K.; Friedrich, C.; Stallmeyer, B.; Coffey, A.J.; Grace, A.; Zumhagen, S.; 
Seebohm, G.; Ortiz-Bonnin, B.; Rinné, S.; Sachse, F.B.; et al. Gain-of-function mutations in the calcium channel CACNA1C (Cav1.2) cause non-syndromic long-QT but not Timothy syndrome. J Mol Cell Cardiol 2015, 80, 186-195.

96. Birey, F.; Andersen, J.; Makinson, C.D.; Islam, S.; Wei, W.; Huber, N.; Fan, C.H.; Metzler, K.R.; Panagiotakos, G.; Thom, N.; et al. Assembly of functionally integrated human forebrain spheroids. Nature 2017, 545, 54.

97. Uher, R. Gene-Environment Interactions in Severe Mental Illness. Frontiers Psychiatry 2014, 5, 48 .

98. Assary, E.; Vincent, J.; Keers, R.; Pluess, M. Gene-environment interaction and psychiatric disorders: Review and future directions. Seminars in Cell \& Developmental Biology 2018, 77, $133-143$.

99. Sklar, P. Linkage Analysis In Psychiatric Disorders: The Emerging Picture. Annual review of genomics and human genetics 2002, 3, 371-413.

100. Umesh, S.; Nizamie, S. Genetics in psychiatry. Indian Journal of Human Genetics 2014, 20, $120-128$.

101. Gratten, J.; Wray, N.R.; Keller, M.C.; Visscher, P.M. Large-scale genomics unveils the genetic architecture of psychiatric disorders. Nature Neuroscience 2014, 17, 782. 
102. Gelernter, J. Genetics of Complex Traits in Psychiatry. Biological Psychiatry 2015, 77, 3642.

103. GAIN Collaborative Research Group; Manolio, T.A.; Rodriguez, L.; Brooks, L.; Abecasis, G.; of Psoriasis, C.; Ballinger, D.; Daly, M.; Donnelly, P.; Faraone, S.V.; et al. New models of collaboration in genome-wide association studies: the Genetic Association Information Network. Nature Genetics 2007, 39, 1045-1051.

104. Sullivan, P.F. The Psychiatric GWAS Consortium: Big Science Comes to Psychiatry. Neuron 2010, 68, 182-186.

105. Demkow, U.; Wolańczyk, T. Genetic tests in major psychiatric disorders-integrating molecular medicine with clinical psychiatry — why is it so difficult? Translational Psychiatry 2017, 7, e1151.

106. Warr, A.; Robert, C.; Hume, D.; Archibald, A.; Deeb, N.; Watson, M. Exome Sequencing: Current and Future Perspectives. G3: Genes|Genomes|Genetics 2015, 5, 1543-1550.

107. Belkadi, A.; Bolze, A.; Itan, Y.; Cobat, A.; Vincent, Q.B.; Antipenko, A.; Shang, L.; Boisson, B.; Casanova, J.-L.; Abel, L. Whole-genome sequencing is more powerful than wholeexome sequencing for detecting exome variants. Proceedings of the National Academy of Sciences 2015, 112, 5473-5478. 
108. Wang, W.; Corominas, R.; Lin, G. De novo Mutations From Whole Exome Sequencing in Neurodevelopmental and Psychiatric Disorders: From Discovery to Application. Frontiers in Genetics 2019, 10, 258.

109. Le, T.T.; Savitz, J.; Suzuki, H.; Misaki, M.; Teague, K.T.; White, B.C.; Marino, J.H.; Wiley, G.; Gaffney, P.M.; Drevets, W.C.; et al. Identification and replication of RNA-Seq gene network modules associated with depression severity. Translational Psychiatry 2018, 8, 180.

110. Pongrac, J.; Middleton, F.A.; Lewis, D.A.; Levitt, P.; Mirnics, K. Gene Expression Profiling with DNA Microarrays: Advancing Our Understanding of Psychiatric Disorders. Neurochem Res 2002, 27, 1049-1063.

111. Williams, N.M.; Zaharieva, I.; Martin, A.; Langley, K.; Mantripragada, K.; Fossdal, R.;

Stefansson, H.; Stefansson, K.; Magnusson, P.; Gudmundsson, O.O.; et al. Rare chromosomal deletions and duplications in attention-deficit hyperactivity disorder: a genome-wide analysis. Lancet (London, England) 2010, 376, 1401-8.

112. Malhotra, D.; Sebat, J. CNVs: harbingers of a rare variant revolution in psychiatric genetics. Cell 2012, 148, 1223-41.

113. Rees, E.; Walters, J.T.; Georgieva, L.; Isles, A.R.; Chambert, K.D.; Richards, A.L.; Mahoney-Davies, G.; Legge, S.E.; Moran, J.L.; McCarroll, S.A.; et al. Analysis of copy number 
variations at 15 schizophrenia-associated loci. The British journal of psychiatry : the journal of mental science 2014, 204, 108-14.

114. Kirov, G.; Rees, E.; Walters, J.T.; Escott-Price, V.; Georgieva, L.; Richards, A.L.;

Chambert, K.D.; Davies, G.; Legge, S.E.; Moran, J.L.; et al. The penetrance of copy number variations for schizophrenia and developmental delay. Biological psychiatry 2014, 75, 378-85.

115. Green, E.; Rees, E.; Walters, J.; Smith, K.-G.G.; Forty, L.; Grozeva, D.; Moran, J.; Sklar, P.; Ripke, S.; Chambert, K.; et al. Copy number variation in bipolar disorder. Molecular psychiatry 2016, 21, 89-93.

116. Kushima, I.; Aleksic, B.; Nakatochi, M.; Shimamura, T.; Okada, T.; Uno, Y.; Morikawa, M.; Ishizuka, K.; Shiino, T.; Kimura, H.; et al. Comparative Analyses of Copy-Number Variation in Autism Spectrum Disorder and Schizophrenia Reveal Etiological Overlap and Biological Insights. Cell Reports 2018, 24, 2838-2856.

117. Rees, E.; Kendall, K.; Pardiñas, A.F.; Legge, S.E.; Pocklington, A.; Escott-Price, V.; MacCabe, J.H.; Collier, D.A.; Holmans, P.; O’Donovan, M.C.; et al. Analysis of Intellectual Disability Copy Number Variants for Association With Schizophrenia. JAMA Psychiatry 2016, $73,963$.

118. Xia, J.; Gill, E.E.; Hancock, R.E. NetworkAnalyst for statistical, visual and network-based meta-analysis of gene expression data. Nat Protoc 2015, 10, 823-844. 
119. GTEx Consortium.; Ardlie, K.; Deluca, D.; Segre, A.; Sullivan, T.; Young, T.; Gelfand, E.; Trowbridge, C.; Maller, J.; Tukiainen, T.; et al. The Genotype-Tissue Expression (GTEx) pilot analysis: Multitissue gene regulation in humans. Science 2015, 348, 648-660.

120. Gilman, S.R.; Chang, J.; Xu, B.; Bawa, T.S.; Gogos, J.A.; Karayiorgou, M.; Vitkup, D. Diverse types of genetic variation converge on functional gene networks involved in schizophrenia. Nat Neurosci 2012, 15, 1723.

121. Fromer, M.; Pocklington, A.J.; Kavanagh, D.H.; Williams, H.J.; Dwyer, S.; Gormley, P.; Georgieva, L.; Rees, E.; Palta, P.; Ruderfer, D.M.; et al. De novo mutations in schizophrenia implicate synaptic networks. Nature 2014, 506, 179.

122. Parikshak, N.N.; Gandal, M.J.; Geschwind, D.H. Systems biology and gene networks in neurodevelopmental and neurodegenerative disorders. Nat Rev Genet 2015, 16, nrg3934.

123. Breen; Maihofer, A.; Glatt, S.; Tylee, D.; Chandler, S.; Tsuang, M.; Risbrough, V.; Baker, D.; O’Connor, D.; Nievergelt, C.; et al. Gene networks specific for innate immunity define posttraumatic stress disorder. Molecular Psychiatry 2015, 20, 1538.

124. European Networks of National Networks studying Gene-Environment Interactions in Schizophrenia (EU-GEI).; van Os, J.; Rutten, B.P.; Myin-Germeys, I.; Delespaul, P.; Viechtbauer, W.; van Zelst, C.; Bruggeman, R.; Reininghaus, U.; Morgan, C.; et al. Identifying 
Gene-Environment Interactions in Schizophrenia: Contemporary Challenges for Integrated, Large-scale Investigations. Schizophrenia Bull 2014, 40, 729-736.

125. Tordjman, S.; Somogyi, E.; Coulon, N.; Kermarrec, S.; Cohen, D.; Bronsard, G.; Bonnot, O.; Weismann-Arcache, C.; Botbol, M.; Lauth, B.; et al. Gene $\times$ Environment Interactions in Autism Spectrum Disorders: Role of Epigenetic Mechanisms. Frontiers Psychiatry 2014, $5,53$.

126. Dick, D.M.; Agrawal, A.; Keller, M.C.; Adkins, A.; Aliev, F.; Monroe, S.; Hewitt, J.K.; Kendler, K.S.; Sher, K.J. Candidate Gene-Environment Interaction Research. Perspect Psychol Sci 2015, 10, 37-59.

127. Isvoranu, A.-M.; Borsboom, D.; van Os, J.; Guloksuz, S. A Network Approach to Environmental Impact in Psychotic Disorder: Brief Theoretical Framework. Schizophrenia Bull 2016, 42, 870-873.

128. Chen, Y.; Baram, T.Z. Toward Understanding How Early-Life Stress Reprograms Cognitive and Emotional Brain Networks. Neuropsychopharmacol 2016, 41, 197.

129. Taylor, M.J.; Martin, J.; Lu, Y.; Brikell, I.; Lundström, S.; Larsson, H.; Lichtenstein, P. Association of Genetic Risk Factors for Psychiatric Disorders and Traits of These Disorders in a Swedish Population Twin Sample. JAMA Psychiatry 2019, 76, 280-289.

130. Iacono, W.G. Endophenotypes in psychiatric disease: prospects and challenges. Genome 
Medicine 2018, 10, 11.

131. Flint, J.; Munafo, M.R. The endophenotype concept in psychiatric genetics. Psychol Med 2007, 37, 163-180.

132. Bigos, K.L.; Mattay, V.S.; Callicott, J.H.; Straub, R.E.; Vakkalanka, R.; Kolachana, B.; Hyde, T.M.; Lipska, B.K.; Kleinman, J.E.; Weinberger, D.R. Genetic Variation in CACNA1C Affects Brain Circuitries Related to Mental Illness. Archives of General Psychiatry 2010, 67, 939-945.

133. Stephan, K.; Mathys, C. Computational approaches to psychiatry. Curr Opin Neurobiol 2014, 25, 85-92.

134. Friston, K.J.; Stephan, K.; Montague, R.; Dolan, R.J. Computational psychiatry: the brain as a phantastic organ. Lancet Psychiatry 2014, 1, 148-158.

135. Wang, X.-J.; Krystal, J.H. Computational Psychiatry. Neuron 2014, 84, 638-654.

136. Huys, Q.J.; Maia, T.V.; Frank, M.J. Computational psychiatry as a bridge from neuroscience to clinical applications. Nature Neuroscience 2016, 19, 404-413.

137. Rosenberg, A.; Patterson, J.; Angelaki, D.E. A computational perspective on autism. Proc National Acad Sci 2015, 112, 9158-9165. 
138. Hauser, T.U.; Fiore, V.G.; Moutoussis, M.; Dolan, R.J. Computational Psychiatry of ADHD: Neural Gain Impairments across Marrian Levels of Analysis. Trends Neurosci 2016, 39, 63-73.

139. Krystal, J.H.; Murray, J.D.; Chekroud, A.M.; Corlett, P.R.; Yang, G.; Wang, X.-J.; Anticevic, A. Computational Psychiatry and the Challenge of Schizophrenia. Schizophrenia Bull 2017, 43, sbx025.

140. Wang, D.; Liu, S.; Warrell, J.; Won, H.; Shi, X.; Navarro, F.C.; Clarke, D.; Gu, M.; Emani, P.; Yang, Y.T. Comprehensive functional genomic resource and integrative model for the human brain. Science 2018, 362, eaat8464.

141. Wang, D.; Liu, S.; Warrell, J.; Won, H.; Shi, X.; Navarro, F.C.; Clarke, D.; Gu, M.; Emani, P.; Yang, Y.T.; et al. Comprehensive functional genomic resource and integrative model for the human brain. Science 2018, 362, eaat8464.

142. Fromer, M.; Roussos, P.; Sieberts, S.K.; Johnson, J.S.; Kavanagh, D.H.; Perumal, T.M.; Ruderfer, D.M.; Oh, E.C.; Topol, A.; Shah, H.R.; et al. Gene expression elucidates functional impact of polygenic risk for schizophrenia. Nature neuroscience 2016, 19, 1442-1453.

143. Akbarian, S.; Liu, C.; Knowles, J.A.; Vaccarino, F.M.; Farnham, P.J.; Crawford, G.E.; Jaffe, A.E.; Pinto, D.; Dracheva, S.; et al. The PsychENCODE project. Nat Neurosci 2015, 18, 
$1707-1712$.

144. The ENCODE Project Consortium. An integrated encyclopedia of DNA elements in the human genome. Nature 2012, 489, 57.

145. Davis, C.A.; Hitz, B.C.; Sloan, C.A.; Chan, E.T.; vidson, J.; Gabdank, I.; Hilton, J.A.; Jain, K.; Baymuradov, U.K.; Narayanan, A.K.; et al. The Encyclopedia of DNA elements (ENCODE): data portal update. Nucleic acids research 2018, 46, D794-D801.

146. Bernstein, B.E.; Stamatoyannopoulos, J.A.; Costello, J.F.; Ren, B.; Milosavljevic, A.; Meissner, A.; Kellis, M.; Marra, M.A.; Beaudet, A.L.; Ecker, J.R.; et al. The NIH Roadmap Epigenomics Mapping Consortium. Nature biotechnology 2010, 28, 1045-8.

147. Lonsdale, J.; Thomas, J.; Salvatore, M.; Phillips, R.; Lo, E.; Shad, S.; Hasz, R.; Walters, G.; Garcia, F.; Young, N.; et al. The Genotype-Tissue Expression (GTEx) project. Nat Genet 2013, 45, 580 .

148. Stranger, B.E.; Brigham, L.E.; Hasz, R.; Hunter, M.; Johns, C.; Johnson, M.; Kopen, G.; Leinweber, W.F.; Lonsdale, J.T.; nald, A.; et al. Enhancing GTEx by bridging the gaps between genotype, gene expression, and disease. Nat Genet 2017, 49, 1664.

149. Hofmann, F.; Flockerzi, V.; Kahl, S.; Wegener, J.W. L-type CaV1.2 calcium channels: from in vitro findings to in vivo function. Physiological reviews 2014, 94, 303-26. 
150. Striessnig, J.; Pinggera, A.; Kaur, G.; Bock, G.; Tuluc, P. L-type Ca2+ channels in heart and brain. Wiley Interdiscip Rev Membr Transp Signal 2014, 3, 15-38.

151. Ortner, N.J.; Striessnig, J. L-type calcium channels as drug targets in CNS disorders. Channels 2015, 10, 7-13.

152. Kabir, Z.D.; Martínez-Rivera, A.; Rajadhyaksha, A.M. From Gene to Behavior: L-Type Calcium Channel Mechanisms Underlying Neuropsychiatric Symptoms. Neurotherapeutics 2017, 14, 588-613.

153. Ferreira, M.A.; O’Donovan, M.C.; Meng, Y.A.; Jones, I.R.; Ruderfer, D.M.; Jones, L.; Fan, J.; Kirov, G.; Perlis, R.H.; et al. Collaborative genome-wide association analysis supports a role for ANK3 and CACNA1C in bipolar disorder. Nat Genet 2008, 40, 1056-1058.

154. Liu, Y.; Blackwood, D.; Caesar, S.; de Geus, E.; Farmer, A.; Ferreira, M.; Ferrier, I.; Fraser, C.; Gordon-Smith, K.; et al. Meta-analysis of genome-wide association data of bipolar disorder and major depressive disorder. Mol Psychiatr 2011, 16, 2.

155. Cross-Disorder Group of the Psychiatry Genomics Consortium. Identification of risk loci with shared effects on five major psychiatric disorders: a genome-wide analysis. The Lancet 2013, 381, 1371-1379. 
156. Ruderfer, D.; Fanous, A.; Ripke, S.; McQuillin, A.; Amdur, R.; of Consortium, S.; of Consortium, B.; of Consortium, C.-D.; Gejman, P.; O’Donovan, M.; et al. Polygenic dissection of diagnosis and clinical dimensions of bipolar disorder and schizophrenia. Molecular Psychiatry 2014, 19, 1017.

157. Gershon, E.; Grennan, K.; Busnello, J.; Badner, J.; Ovsiew, F.; Memon, S.; AllieyRodriguez, N.; Cooper, J.; Romanos, B.; Liu, C. A rare mutation of CACNA1C in a patient with bipolar disorder, and decreased gene expression associated with a bipolar-associated common SNP of CACNA1C in brain. Mol Psychiatr 2014, 19, 890.

158. Yoshimizu, T.; Pan, J.; Mungenast, A.; Madison, J.; Su, S.; Ketterman, J.; Ongur, D.; McPhie, D.; Cohen, B.; Perlis, R.; et al. Functional implications of a psychiatric risk variant within CACNA1C in induced human neurons. Mol Psychiatr 2015, 20, 162-169.

159. Starnawska, A.; Demontis, D.; Pen, A.; Hedemand, A.; Nielsen, A.; Staunstrup, N.; Grove, J.; Als, T.; Jarram, A.; O’Brien, N.; et al. CACNA1C hypermethylation is associated with bipolar disorder. Transl Psychiat 2016, 6, e831.

160. Balaraman, Y.; Lahiri, D.K.; Nurnberger, J.I. Variants in Ion Channel Genes Link Phenotypic Features of Bipolar Illness to Specific Neurobiological Process Domains. Molecular Neuropsychiatry 2015, 1, 23-35.

161. Soeiro-de-Souza, M.; Lafer, B.; Moreno, R.; Nery, F.; Chile, T.; Chaim, K.; da Leite, C.C.; 
Machado-Vieira, R.; Otaduy, M.; Vallada, H. The CACNA1C risk allele rs1006737 is associated with age-related prefrontal cortical thinning in bipolar I disorder. Transl Psychiat 2017, 7, e1086.

162. Sumner, J.A.; Sheridan, M.A.; Drury, S.S.; Esteves, K.C.; Walsh, K.; Koenen, K.C.; McLaughlin, K.A. Variation in CACNA1C is Associated with Amygdala Structure and Function in Adolescents. Journal of child and adolescent psychopharmacology 2015, 25, 701-10.

163. Tesli, M.; Skatun, K.C.; Ousdal, O.; Brown, A.; Thoresen, C.; Agartz, I.; Melle, I.; jan Djurovic; Jensen, J.; Andreassen, O.A. CACNA1C Risk Variant and Amygdala Activity in Bipolar Disorder, Schizophrenia and Healthy Controls. Plos One 2013, 8, e56970.

164. Soeiro-de-Souza, M.; Otaduy, M.; Dias, C.; Bio, D.S.; Machado-Vieira, R.; Moreno, R. The impact of the CACNA1C risk allele on limbic structures and facial emotions recognition in bipolar disorder subjects and healthy controls. Journal of Affective Disorders 2012, 141, 94-101.

165. Nieratschker, V.; Brückmann, C.; Plewnia, C. CACNA1C risk variant affects facial emotion recognition in healthy individuals. Scientific Reports 2015, 5, 17349.

166. Witt, S.H.; Kleindienst, N.; Frank, J.; Treutlein, J.; Mühleisen, T.; Degenhardt, F.;

Jungkunz, M.; Krumm, B.; Cichon, S.; Tadic, A.; et al. Analysis of genome-wide significant bipolar disorder genes in borderline personality disorder. Psychiatric Genetics 2014, 24, $262-$ 265. 
167. Nia, A.; Eveleth, M.C.; Gabbay, J.M.; Hassan, Y.J.; Zhang, B.; Perez-Rodriguez, M.M. Past, present, and future of genetic research in borderline personality disorder. Curr Opin Psychology 2018, 21, 60-68.

168. Pasparakis, E.; Koiliari, E.; Zouraraki, C.; Tsapakis, E.-M.; Roussos, P.; Giakoumaki, S.G.; Bitsios, P. The effects of the CACNA1C rs 1006737 A/G on affective startle modulation in healthy males. Eur Psychiat 2015, 30, 492-498.

169. Mallas, E.; Carletti, F.; Chaddock, C.; Shergill, S.; Woolley, J.; Picchioni, M.; nald, C.; Toulopoulou, T.; Kravariti, E.; Kalidindi, S.; et al. The impact of CACNA1C gene, and its epistasis with ZNF804A, on white matter microstructure in health, schizophrenia and bipolar disorder1. Genes, Brain and Behavior 2017, 16, 479-488.

170. Casamassima, F.; Huang, J.; Fava, M.; Sachs, G.S.; Smoller, J.W.; Cassano, G.B.; Lattanzi, L.; Fagerness, J.; Stange, J.P.; Perlis, R.H. Phenotypic effects of a bipolar liability gene among individuals with major depressive disorder. American Journal of Medical Genetics Part B: Neuropsychiatric Genetics 2010, 153B, 303-309.

171. Fabbri, C.; Corponi, F.; Albani, D.; Raimondi, I.; Forloni, G.; Schruers, K.; Kasper, S.; Kautzky, A.; Zohar, J.; Souery, D.; et al. Pleiotropic genes in psychiatry: Calcium channels and the stress-related FKBP5 gene in antidepressant resistance. Progress in NeuroPsychopharmacology and Biological Psychiatry 2018, 81, 203-210. 
172. Schizophrenia Working Group of the Psychiatry Genomics Consortium.; Ripke, S.; Neale, B.M.; Corvin, A.; Walters, J.T.; Farh, K.-H.; Holmans, P.A.; Lee, P.; Bulik-Sullivan, B.; Collier, D.A.; et al. Biological insights from 108 schizophrenia-associated genetic loci. Nature 2014, $511,421$.

173. Goes, F.S.; McGrath, J.; Avramopoulos, D.; Wolyniec, P.; Pirooznia, M.; Ruczinski, I.; Nestadt, G.; Kenny, E.E.; Vacic, V.; Peters, I.; et al. Genome-wide association study of schizophrenia in Ashkenazi Jews. American Journal of Medical Genetics Part B:

Neuropsychiatric Genetics 2015, 168, 649-659.

174. Autism Spectrum Disorders Working Group of the Psychiatry Genomics Consortium. Metaanalysis of GWAS of over 16,000 individuals with autism spectrum disorder highlights a novel locus at 10q24.32 and a significant overlap with schizophrenia. Molecular Autism 2017, 8, 21.

175. Pardiñas, A.F.; Holmans, P.; Pocklington, A.J.; Escott-Price, V.; Ripke, S.; Carrera, N.;

Legge, S.E.; Bishop, S.; Cameron, D.; Hamshere, M.L.; et al. Common schizophrenia alleles are enriched in mutation-intolerant genes and in regions under strong background selection. Nature Genetics 2018, 50, 381-389.

176. Zheng, F.; Zhang, Y.; Xie, W.; Li, W.; Jin, C.; Mi, W.; Wang, F.; Ma, W.; Ma, C.; Yang, Y.; et al. Further evidence for genetic association of CACNA1C and schizophrenia: New risk loci in a Han Chinese population and a meta-analysis. Schizophr Res 2014, 152, 105-110. 
177. Cosgrove, D.; Mothersill, O.; Kendall, K.; Konte, B.; Harold, D.; Giegling, I.; Hartmann, A.; Richards, A.; Mantripragada, K.; Consortium, T.; et al. Cognitive Characterization of Schizophrenia Risk Variants Involved in Synaptic Transmission: Evidence of CACNA1C's Role in Working Memory. Neuropsychopharmacol 2017, 42, 2612.

178. Bustillo, J.R.; Patel, V.; Jones, T.; Jung, R.; Payaknait, N.; Qualls, C.; Canive, J.M.; Liu, J.; Perrone-Bizzozero, N.; Calhoun, V.D.; et al. Risk-Conferring Glutamatergic Genes and Brain Glutamate Plus Glutamine in Schizophrenia. Frontiers Psychiatry 2017, 8, 79.

179. Murphy, M.J.; Peterson, M.J. Sleep Disturbances in Depression. Sleep Medicine Clin 2015, $10,17-23$.

180. Ng, T.H.; Chung, K.-F.; Ho, F.; Yeung, W.-F.; Yung, K.-P.; Lam, T.-H. Sleep-wake disturbance in interepisode bipolar disorder and high-risk individuals: A systematic review and meta-analysis. Sleep Med Rev 2015, 20, 46-58.

181. Manoach, D.S.; Pan, J.Q.; Purcell, S.M.; Stickgold, R. Reduced Sleep Spindles in Schizophrenia: A Treatable Endophenotype That Links Risk Genes to Impaired Cognition? Biol Psychiat 2016, 80, 599-608.

182. Shimada, M.; Miyagawa, T.; Kawashima, M.; Tanaka, S.; Honda, Y.; Honda, M.;

Tokunaga, K. An approach based on a genome-wide association study reveals candidate loci for narcolepsy. Human Genetics 2010, 128, 433-441. 
183. Byrne, E.M.; Gehrman, P.R.; Medland, S.E.; Nyholt, D.R.; Heath, A.C.; Madden, P.A.; Hickie, I.B.; ijn, C.; Henders, A.K.; Montgomery, G.W.; et al. A genome-wide association study of sleep habits and insomnia. American Journal of Medical Genetics Part B: Neuropsychiatric Genetics 2013, 162, 439-451.

184. Parsons, M.J.; Lester, K.J.; Barclay, N.L.; Nolan, P.M.; Eley, T.C.; Gregory, A.M. Replication of Genome-Wide association studies (GWAS) loci for sleep in the British G1219 cohort. American Journal of Medical Genetics Part B: Neuropsychiatric Genetics 2013, 162, 431-438.

185. Kantojärvi, K.; Liuhanen, J.; Saarenpää-Heikkilä, O.; Satomaa, A.-L.; Kylliäinen, A.; Pölkki, P.; Jaatela, J.; Toivola, A.; Milani, L.; Himanen, S.-L.; et al. Variants in calcium voltagegated channel subunit Alpha1 C-gene (CACNA1C) are associated with sleep latency in infants. PLOS ONE 2017, 12, e0180652.

186. Amare, A.T.; Vaez, A.; Hsu, Y.-H.; Direk, N.; Kamali, Z.; Howard, D.M.; McIntosh, A.M.; Tiemeier, H.; Bültmann, U.; Snieder, H.; et al. Bivariate genome-wide association analyses of the broad depression phenotype combined with major depressive disorder, bipolar disorder or schizophrenia reveal eight novel genetic loci for depression. Molecular Psychiatry 2019, 1-10.

187. Dedic, N.; Pöhlmann, M.; Richter, J.; Mehta, D.; Czamara, D.; Metzger, M.; Dine, J.;

Bedenk, B.; Hartmann, J.; Wagner, K.; et al. Cross-disorder risk gene CACNA1C differentially 
modulates susceptibility to psychiatric disorders during development and adulthood. Molecular Psychiatry 2017, 23, 533.

188. Porcelli, S.; Lee, S.-J.; Han, C.; Patkar, A.A.; Serretti, A.; Pae, C.-U. CACNA1C gene and schizophrenia. Psychiatric Genetics 2015, 25, 163-167.

189. Jan, W.-C.; Yang, S.-Y.; Chuang, L.-C.; Lu, R.-B.; Lu, M.-K.; Sun, S.H.; Kuo, P.-H. Exploring the associations between genetic variants in genes encoding for subunits of calcium channel and subtypes of bipolar disorder. Journal of Affective Disorders 2014, 157, 80-86.

190. Lu, A.; Dai, X.; Martinez-Agosto, J.A.; Cantor, R.M. Support for calcium channel gene defects in autism spectrum disorders. Molecular Autism 2012, 3, 18.

191. Skafidas, E.; Testa, R.; Zantomio, D.; Chana, G.; Everall, I.; Pantelis, C. Predicting the diagnosis of autism spectrum disorder using gene pathway analysis. Molecular Psychiatry 2014, $19,504$.

192. Purcell, S.M.; Moran, J.L.; Fromer, M.; Ruderfer, D.; Solovieff, N.; Roussos, P.; O’Dushlaine, C.; Chambert, K.; Bergen, S.E.; Kähler, A.; et al. A polygenic burden of rare disruptive mutations in schizophrenia. Nature 2014, 506, 185.

193. Ament, S.A.; Szelinger, S.; Glusman, G.; Ashworth, J.; Hou, L.; Akula, N.; Shekhtman, T.; Badner, J.A.; Brunkow, M.E.; Mauldin, D.E.; et al. Rare variants in neuronal excitability genes 
influence risk for bipolar disorder. Proceedings of the National Academy of Sciences 2015, 112, 3576-3581.

194. Ross, J.; Gedvilaite, E.; Badner, J.A.; Erdman, C.; Baird, L.; Matsunami, N.; Leppert, M.; Xing, J.; Byerley, W. A Rare Variant in CACNA1D Segregates with 7 Bipolar I Disorder Cases in a Large Pedigree. Mol Neuropsychiatry 2016, 2, 145-150.

195. Guan, F.; Li, L.; Qiao, C.; Chen, G.; Yan, T.; Li, T.; Zhang, T.; Liu, X. Evaluation of genetic susceptibility of common variants in CACNA1D with schizophrenia in Han Chinese. Sci Rep-uk 2015, 5, 12935.

196. Li, Z.; Chen, J.; Yu, H.; He, L.; Xu, Y.; Zhang, D.; Yi, Q.; Li, C.; Li, X.; Shen, J.; et al. Genome-wide association analysis identifies 30 new susceptibility loci for schizophrenia. Nat Genet 2017, 49, ng.3973.

197. Ikeda, M.; Takahashi, A.; Kamatani, Y.; Momozawa, Y.; Saito, T.; Kondo, K.; Shimasaki, A.; Kawase, K.; Sakusabe, T.; Iwayama, Y.; et al. Genome-Wide Association Study Detected Novel Susceptibility Genes for Schizophrenia and Shared Trans-Populations/Diseases Genetic Effect. Schizophrenia Bull 2018.

198. O’Roak, B.J.; Vives, L.; Girirajan, S.; Karakoc, E.; Krumm, N.; Coe, B.P.; Levy, R.; Ko, A.; Lee, C.; Smith, J.D.; et al. Sporadic autism exomes reveal a highly interconnected protein network of de novo mutations. Nature 2012, 485, 246. 
199. Iossifov, I.; O’Roak, B.J.; Sanders, S.J.; Ronemus, M.; Krumm, N.; Levy, D.; Stessman, H.A.; Witherspoon, K.T.; Vives, L.; Patterson, K.E.; et al. The contribution of de novo coding mutations to autism spectrum disorder. Nature 2014, 515, 216.

200. Lek, M.; Karczewski, K.J.; Minikel, E.V.; Samocha, K.E.; Banks, E.; Fennell, T.;

O’Donnell-Luria, A.H.; Ware, J.S.; Hill, A.J.; Cummings, B.B.; et al. Analysis of protein-coding genetic variation in 60,706 humans. Nature 2016, 536, 285.

201. Pinggera, A.; Lieb, A.; Benedetti, B.; Lampert, M.; Monteleone, S.; Liedl, K.R.; Tuluc, P.; Striessnig, J. CACNA1D De Novo Mutations in Autism Spectrum Disorders Activate Cav1.3 LType Calcium Channels. Biol Psychiat 2015, 77, 816-822.

202. Limpitikul, W.B.; Dick, I.E.; Ben-Johny, M.; Yue, D.T. An autism-associated mutation in CaV1.3 channels has opposing effects on voltage- and Ca2+-dependent regulation. Sci Rep-uk 2016, 6,27235 .

203. Pinggera, A.; Mackenroth, L.; Rump, A.; Schallner, J.; Beleggia, F.; Wollnik, B.; Striessnig, J. New gain-of-function mutations show $C A C N A 1 D$ as recurrently mutated gene autism spectrum disorders and epilepsy. Human Molecular Genetics 2017.

204. Pinggera, A.; Striessnig, J. Cav1.3 (CACNA1D) L-type Ca2+ channel dysfunction in CNS disorders. The Journal of Physiology 2016, 594, 5839-5849. 
205. Weyn-Vanhentenryck, S.M.; Mele, A.; Yan, Q.; Sun, S.; Farny, N.; Zhang, Z.; Xue, C.; Herre, M.; Silver, P.A.; Zhang, M.Q.; et al. HITS-CLIP and Integrative Modeling Define the Rbfox Splicing-Regulatory Network Linked to Brain Development and Autism. Cell Reports 2014, 6, 1139-1152.

206. Garza-Lopez, E.; Lopez, J.A.; Hagen, J.; Sheffer, R.; Meiner, V.; Lee, A. Role of a conserved glutamine in the function of voltage-gated $\mathrm{Ca} 2+$ channels revealed by a mutation in human CACNA1D. J Biol Chem 2018, 293, 14444-14454.

207. Damaj, L.; Lupien-Meilleur, A.; Lortie, A.; Riou, É.; Ospina, L.H.; Gagnon, L.; Vanasse, C.; Rossignol, E. CACNA1A haploinsufficiency causes cognitive impairment, autism and epileptic encephalopathy with mild cerebellar symptoms. European Journal of Human Genetics 2015, 23, 1505 .

208. Indelicato, E.; Nachbauer, W.; Karner, E.; Eigentler, A.; Wagner, M.; Unterberger, I.; Poewe, W.; lazer; Boesch, S. The neuropsychiatric phenotype in CACNA1A mutations: a retrospective single center study and review of the literature. European Journal of Neurology 2019, 26, 66-e7.

209. Gandal, M.J.; Zhang, P.; Hadjimichael, E.; Walker, R.L.; Chen, C.; Liu, S.; Won, H.; van Bakel, H.; Varghese, M.; Wang, Y.; et al. Transcriptome-wide isoform-level dysregulation in ASD, schizophrenia, and bipolar disorder. Science 2018, 362, eaat8127. 
210. Li, Q.; Wineinger, N.E.; Fu, D.-J.; Libiger, O.; Alphs, L.; Savitz, A.; hari Gopal; Cohen, N.; Schork, N.J. Genome-wide association study of paliperidone efficacy. Pharmacogenetics and Genomics 2017, 27, 7-18.

211. O’Connell, K.S.; McGregor, N.W.; Malhotra, A.; Lencz, T.; Emsley, R.; Warnich, L. Variation within voltage-gated calcium channel genes and antipsychotic treatment response in a South African first episode schizophrenia cohort. Pharmacogenomics J 2019, 19, 109-114.

212. Glessner, J.T.; Reilly, M.P.; Kim, C.E.; Takahashi, N.; Albano, A.; Hou, C.; Bradfield, J.P.; Zhang, H.; Sleiman, P.M.; Flory, J.H.; et al. Strong synaptic transmission impact by copy number variations in schizophrenia. Proceedings of the National Academy of Sciences 2010, 107, $10584-10589$.

213. Yatsenko, S.A.; Hixson, P.; Roney, E.K.; Scott, D.A.; Schaaf, C.P.; Ng, Y.; Palmer, R.; Fisher, R.B.; Patel, A.; Cheung, S.; et al. Human subtelomeric copy number gains suggest a DNA replication mechanism for formation: beyond breakage-fusion-bridge for telomere stabilization. Human Genetics 2012, 131, 1895-1910.

214. Pinto, D.; Delaby, E.; Merico, D.; Barbosa, M.; Merikangas, A.; Klei, L.; Thiruvahindrapuram, B.; Xu, X.; Ziman, R.; Wang, Z.; et al. Convergence of Genes and Cellular Pathways Dysregulated in Autism Spectrum Disorders. The American Journal of Human Genetics 2014, 94, 677-694. 
215. Tombácz, D.; Maróti, Z.; Kalmár, T.; Csabai, Z.; Balázs, Z.; Takahashi, S.; Palkovits, M.; Snyder, M.; Boldogkői, Z. High-Coverage Whole-Exome Sequencing Identifies Candidate Genes for Suicide in Victims with Major Depressive Disorder. Sci Rep-uk 2017, 7, 7106.

216. Cantor, R.M.; Kono, N.; Duvall, J.A.; Alvarez-Retuerto, A.; Stone, J.L.; Alarcón, M.; Nelson, S.F.; Geschwind, D.H. Replication of Autism Linkage: Fine-Mapping Peak at 17q21. Am J Hum Genetics 2005, 76, 1050-1056.

217. Howard, D.M.; Adams, M.J.; Clarke, T.-K.; Hafferty, J.D.; Gibson, J.; Shirali, M.; Coleman, J.R.; Hagenaars, S.P.; Ward, J.; et al. Genome-wide meta-analysis of depression identifies 102 independent variants and highlights the importance of the prefrontal brain regions. Nature Neuroscience 2019, 22, 343-352.

218. Okbay, A.; Baselmans, B.M.; Neve, J.-E.; Turley, P.; Nivard, M.G.; Fontana, M.; Meddens, F.S.; Linnér, R.; Rietveld, C.A.; Derringer, J.; et al. Genetic variants associated with subjective well-being, depressive symptoms, and neuroticism identified through genome-wide analyses. Nature Genetics 2016, 48, 624.

219. Lin, E.; Kuo, P.-H.; Liu, Y.-L.; Yu, Y.; Yang, A.C.; Tsai, S.-J. A Deep Learning Approach for Predicting Antidepressant Response in Major Depression Using Clinical and Genetic Biomarkers. Frontiers Psychiatry 2018, 9, 290. 
220. Heck, A.; Fastenrath, M.; Ackermann, S.; Auschra, B.; Bickel, H.; Coynel, D.; Gschwind, L.; Jessen, F.; Kaduszkiewicz, H.; Maier, W.; et al. Converging Genetic and Functional Brain Imaging Evidence Links Neuronal Excitability to Working Memory, Psychiatric Disease, and Brain Activity. Neuron 2014, 81, 1203-1213.

221. Strom, S.; Stone, J.; ten Bosch, J.; Merriman, B.; Cantor, R.; Geschwind, D.; Nelson, S. High-density SNP association study of the 17q21 chromosomal region linked to autism identifies CACNA1G as a novel candidate gene. Molecular Psychiatry 2010, 15, 996.

222. Iossifov, I.; Ronemus, M.; Levy, D.; Wang, Z.; Hakker, I.; Rosenbaum, J.; Yamrom, B.; Lee, Y.; Narzisi, G.; Leotta, A.; et al. De Novo Gene Disruptions in Children on the Autistic Spectrum. Neuron 2012, 74, 285-299.

223. Chemin, J.; Siquier-Pernet, K.; Nicouleau, M.; Barcia, G.; Ahmad, A.; Medina-Cano, D.; Hanein, S.; Altin, N.; Hubert, L.; Bole-Feysot, C.; et al. De novo screening on childhood-onset cerebellar atrophy identifies gain-of-function mutations the $C A C N A 1 G$ calcium channel gene. Brain 2018, 141, 1998-2013.

224. Deciphering Developmental Disorders Study.; Fitzgerald, T.; Gerety, S.; Jones, W.; van Kogelenberg, M.; King, D.; McRae, J.; Morley, K.; Parthiban, V.; Al-Turki, S.; et al. Large-scale discovery of novel genetic causes of developmental disorders. Nature 2015, 519, 223.

225. Splawski, I.; Yoo, D.S.; Stotz, S.C.; Cherry, A.; Clapham, D.E.; Keating, M.T. CACNA1H 
Mutations in Autism Spectrum Disorders. Journal of Biological Chemistry 2006, 281, 2208522091.

226. Chourasia, N.; Osso-Rivera, H.; Ghosh, A.; Allmen, G.; Koenig, M. Expanding the phenotypic spectrum of CACNA1H mutations. Pediatr Neurol 2018, 93, 50-55.

227. Gama, A.; Pochareddy, S.; Li, M.; Jamuar, S.S.; Reiff, R.E.; Lam, A.-T.N.; Sestan, N.; Walsh, C.A. Targeted DNA Sequencing from Autism Spectrum Disorder Brains Implicates Multiple Genetic Mechanisms. Neuron 2015, 88, 910-917.

228. Iossifov, I.; Levy, D.; Allen, J.; Ye, K.; Ronemus, M.; Lee, Y.; Yamrom, B.; Wigler, M. Low load for disruptive mutations in autism genes and their biased transmission. Proceedings of the National Academy of Sciences 2015, 112, E5600-E5607.

229. Takata, A.; Miyake, N.; Tsurusaki, Y.; Fukai, R.; Miyatake, S.; Koshimizu, E.; Kushima, I.; Okada, T.; Morikawa, M.; Uno, Y.; et al. Integrative Analyses of De Novo Mutations Provide Deeper Biological Insights into Autism Spectrum Disorder. Cell Reports 2018, 22, 734-747.

230. Li, W.; Fan, C.; Mäki-Marttunen, T.; Thompson, W.K.; Schork, A.J.; Bettella, F.; of the Consortium, S.; jan Djurovic; le, A.; Andreassen, O.A.; et al. A molecule-based genetic association approach implicates a range of voltage-gated calcium channels associated with schizophrenia. American Journal of Medical Genetics Part B: Neuropsychiatric Genetics 2018, $177,454-467$. 
231. Gulsuner, S.; Walsh, T.; Watts, A.C.; Lee, M.K.; Thornton, A.M.; Casadei, S.; Rippey, C.; Shahin, H.; Nimgaonkar, V.L.; Go, R.; et al. Spatial and Temporal Mapping of De Novo Mutations in Schizophrenia to a Fetal Prefrontal Cortical Network. Cell 2013, 154, 518-529.

232. Andrade, A.; Hope, J.; Allen, A.; Yorgan, V.; Lipscombe, D.; Pan, J. A rare schizophrenia risk variant of CACNA1I disrupts CaV3.3 channel activity. Scientific Reports 2016, 6, 34233.

233. Irish Schizophrenia Genomics Consortium and the Welcome Trust Case Control Consortium 2. Genome-Wide Association Study Implicates HLA-C*01:02 as a Risk Factor at the Major Histocompatibility Complex Locus in Schizophrenia. Biological Psychiatry 2012, 72, $620-628$.

234. Xu, W.; Liu, Y.; Chen, J.; Guo, Q.; Liu, K.; Wen, Z.; Zhou, Z.; Song, Z.; Zhou, J.; He, L.; et al. Genetic risk between the CACNA1I gene and schizophrenia in Chinese Uygur population. Hereditas 2017, 155, 5 .

235. Xie, Y.; Huang, D.; Wei, L.; Luo, X.-J. Further evidence for the genetic association between CACNA1I and schizophrenia. Hereditas 2018, 155, 16.

236. Zhang, T.; Zhu, L.; Ni, T.; Liu, D.; Chen, G.; Yan, Z.; Lin, H.; Guan, F.; Rice, J.P. Voltagegated calcium channel activity and complex related genes and schizophrenia: A systematic investigation based on Han Chinese population. Journal of Psychiatric Research 2018, 106, 99- 
105.

237. Lam, M.; Trampush, J.W.; Yu, J.; Knowles, E.; Davies, G.; Liewald, D.C.; arr, J.; jan Djurovic; Melle, I.; Sundet, K.; et al. Large-Scale Cognitive GWAS Meta-Analysis Reveals Tissue-Specific Neural Expression and Potential Nootropic Drug Targets. Cell Reports 2017, 21, 2597-2613.

238. Merikanto, I.; Utge, S.; Lahti, J.; Kuula, L.; Makkonen, T.; Lahti-Pulkkinen, M.; Heinonen, K.; Räikkönen, K.; Andersson, S.; Strandberg, T.; et al. Genetic risk factors for schizophrenia associate with sleep spindle activity in healthy adolescents. Journal of Sleep Research 2019, 28, e12762.

239. Sanchez-Roige, S.; Fontanillas, P.; Elson, S.L.; Gray, J.C.; de Wit, H.; MacKillop, J.; Palmer, A.A. Genome-wide association studies of impulsive personality traits (BIS-11 and UPPSP) and drug experimentation in up to 22,861 adult research participants identify loci in the CACNA1I and CADM2 genes. The Journal of Neuroscience 2019, 2662-18.

240. Dalley, J.W.; Robbins, T.W. Fractionating impulsivity: neuropsychiatric implications. Nature Reviews Neuroscience 2017, 18, 158-171.

241. Elia, J.; Glessner, J.T.; Wang, K.; Takahashi, N.; Shtir, C.J.; Hadley, D.; Sleiman, P.M.; Zhang, H.; Kim, C.E.; Robison, R.; et al. Genome-wide copy number variation study associates metabotropic glutamate receptor gene networks with attention deficit hyperactivity disorder. 
Nature Genetics 2012, 44, 78.

242. Hussman, J.P.; Chung, R.-H.; Griswold, A.J.; Jaworski, J.M.; Salyakina, D.; Ma, D.; Konidari, I.; Whitehead, P.L.; Vance, J.M.; Martin, E.R.; et al. A noise-reduction GWAS analysis implicates altered regulation of neurite outgrowth and guidance in autism. Molecular Autism 2011, 2, 1 .

243. Geisler, S.; Schöpf, C.L.; Stanika, R.; Kalb, M.; Campiglio, M.; Repetto, D.; Traxler, L.; Missler, M.; Obermair, G.J. Presynaptic $\alpha 2 \delta$-2 calcium channel subunits regulate postsynaptic GABAA-receptor abundance and axonal wiring. Journal of Neuroscience 2019, 39, 2234-18.

244. Ikeda, M.; Shimasaki, A.; Takahashi, A.; Kondo, K.; Saito, T.; Kawase, K.; Esaki, K.; Otsuka, Y.; Mano, K.; Kubo, M.; et al. Genome-Wide Environment Interaction Between Depressive State and Stressful Life Events. The Journal of Clinical Psychiatry 2016, 77, e29e30.

245. Winham, S.J.; Cuellar-Barboza, A.B.; McElroy, S.L.; Oliveros, A.; Crow, S.; Colby, C.L.; Choi, D.-S.; Chauhan, M.; Frye, M.A.; Biernacka, J.M. Bipolar disorder with comorbid binge eating history: A genome-wide association study implicates APOB. J Affect Disorders 2014, $165,151-158$.

246. Rodríguez-López, J.; Sobrino, B.; Amigo, J.; Carrera, N.; Brenlla, J.; Agra, S.; Paz, E.; Carracedo, Á.; Páramo, M.; Arrojo, M.; et al. Identification of putative second genetic hits in 
schizophrenia carriers of high-risk copy number variants and resequencing in additional samples. Eur Arch Psy Clin N 2018, 268, 585-592.

247. Yuen, R.K.; Merico, D.; Bookman, M.; Howe, J.L.; Thiruvahindrapuram, B.; Patel, R.V.; Whitney, J.; Deflaux, N.; Bingham, J.; Wang, Z.; et al. Whole genome sequencing resource identifies 18 new candidate genes for autism spectrum disorder. Nat Neurosci 2017, 20, nn.4524.

248. Rubeis, S.; He, X.; Goldberg, A.P.; Poultney, C.S.; Samocha, K.; Cicek, E.A.; Kou, Y.; Liu, L.; Fromer, M.; Walker, S.; et al. Synaptic, transcriptional and chromatin genes disrupted in autism. Nature 2014, 515, 209.

249. Girirajan, S.; Dennis, M.Y.; Baker, C.; Malig, M.; Coe, B.P.; Campbell, C.D.; Mark, K.; Vu, T.H.; Alkan, C.; Cheng, Z.; et al. Refinement and Discovery of New Hotspots of CopyNumber Variation Associated with Autism Spectrum Disorder. Am J Hum Genetics 2013, 92, $221-237$.

250. Ruzzo, E.K.; Perez-Cano, L.; Jung, J.-Y.; Wang, L.; Kashef-Haghighi, D.; Hartl, C.; Hoekstra, J.; Leventhal, O.; Gandal, M.J.; Paskov, K.; et al. Whole genome sequencing in multiplex families reveals novel inherited and de novo genetic risk in autism. bioRxiv 2018, 338855 .

251. Moons, T.; Hert, M.; Gellens, E.; Gielen, L.; Sweers, K.; Jacqmaert, S.; van Winkel, R.; Vandekerckhove, P.; Claes, S. Genetic Evaluation of Schizophrenia Using the Illumina 
HumanExome Chip. Plos One 2016, 11, e0150464.

252. Li, J.; Yoshikawa, A.; Brennan, M.D.; Ramsey, T.L.; Meltzer, H.Y. Genetic predictors of antipsychotic response to lurasidone identified in a genome wide association study and by schizophrenia risk genes. Schizophr Res 2018, 192, 194-204.

253. Liu, J.; Chen, J.; Perrone-Bizzozero, N.I.; Turner, J.A.; Calhoun, V.D. Regional enrichment analyses on genetic profiles for schizophrenia and bipolar disorder. Schizophr Res 2018, 192, 240-246.

254. Meda, S.A.; Ruaño, G.; Windemuth, A.; O’Neil, K.; Berwise, C.; nn, S.; Boccaccio, L.E.; Narayanan, B.; Kocherla, M.; Sprooten, E.; et al. Multivariate analysis reveals genetic associations of the resting default mode network in psychotic bipolar disorder and schizophrenia. Proceedings of the National Academy of Sciences 2014, 111, E2066-E2075.

255. Qin, N.; Yagel, S.; Momplaisir, M.-L.; Codd, E.E.; D’Andrea, M.R. Molecular Cloning and Characterization of the Human Voltage-Gated Calcium Channel $\alpha 2 \delta-4$ Subunit. Mol Pharmacol 2002, 62, 485-496.

256. Bossche, M.J.; Strazisar, M.; Bruyne, S.; Bervoets, C.; Lenaerts, A.; Zutter, S.; Nordin, A.; Norrback, K.; Goossens, D.; Rijk, P.; et al. Identification of a CACNA2D4 deletion in late onset bipolar disorder patients and implications for the involvement of voltage-dependent calcium channels in psychiatric disorders. American Journal of Medical Genetics Part B: 
Neuropsychiatric Genetics 2012, 159B, 465-475.

257. Prabhu, S.; Pe'er, I. Ultrafast genome-wide scan for SNP-SNP interactions in common complex disease. Genome Research 2012, 22, 2230-2240.

258. Smith, M.; Flodman, P.L.; Gargus, J.J.; Simon, M.T.; Verrell, K.; Haas, R.; Reiner, G.E.; Naviaux, R.; Osann, K.; Spence, A.M.; et al. Mitochondrial and ion channel gene alterations in autism. Biochimica Et Biophysica Acta Bba - Bioenergetics 2012, 1817, 1796-1802.

259. Trikalinos, T.; Karvouni, A.; Zintzaras, E.; Ylisaukko-oja, T.; Peltonen, L.; Järvelä, I.;

Ioannidis, J. A heterogeneity-based genome search meta-analysis for autism-spectrum disorders. Mol Psychiatr 2006, 11, 29.

260. Madison, J.; Zhou, F.; Nigam, A.; Hussain, A.; Barker, D.; Nehme, R.; van der Ven, K.; Hsu, J.; Wolf, P.; Fleishman, M.; et al. Characterization of bipolar disorder patient-specific induced pluripotent stem cells from a family reveals neurodevelopmental and mRNA expression abnormalities. Mol Psychiatr 2015, 20, 703-717.

261. Ripke, S.; O’Dushlaine, C.; Chambert, K.; Moran, J.L.; Kähler, A.K.; Akterin, S.; Bergen, S.E.; Collins, A.L.; Crowley, J.J.; Fromer, M.; et al. Genome-wide association analysis identifies 13 new risk loci for schizophrenia. Nature Genetics 2013, 45, 1150-1159.

262. Giusti-Rodríguez, P.; Sullivan, P.F. The genomics of schizophrenia: update and 
implications. J Clin Invest 2013, 123, 4557-4563.

263. Roussos, P.; Mitchell, A.C.; Voloudakis, G.; Fullard, J.F.; Pothula, V.M.; Tsang, J.; Stahl, E.A.; Georgakopoulos, A.; Ruderfer, D.M.; Charney, A.; et al. A Role for Noncoding Variation in Schizophrenia. Cell Reports 2014, 9, 1417-1429.

264. Juraeva, D.; Haenisch, B.; Zapatka, M.; Frank, J.; Investigators, G.; Group, P.-G.; Witt, S.H.; Mühleisen, T.W.; Treutlein, J.; Strohmaier, J.; et al. Integrated Pathway-Based Approach Identifies Association between Genomic Regions at CTCF and CACNB2 and Schizophrenia. Plos Genet 2014, 10, e1004345.

265. Wang, K.-S.; Liu, X.-F.; Aragam, N. A genome-wide meta-analysis identifies novel loci associated with schizophrenia and bipolar disorder. Schizophrenia Research 2010, 124, 192-199.

266. Andreassen, O.A.; Thompson, W.K.; Schork, A.J.; Ripke, S.; Mattingsdal, M.; Kelsoe, J.R.; Kendler, K.S.; O’Donovan, M.C.; Rujescu, D.; Werge, T.; et al. Improved Detection of Common Variants Associated with Schizophrenia and Bipolar Disorder Using Pleiotropy-Informed Conditional False Discovery Rate. PLoS Genetics 2013, 9, e1003455.

267. Cocchi, E.; Fabbri, C.; Han, C.; Lee, S.-J.; Patkar, A.A.; Masand, P.S.; Pae, C.-U.; Serretti, A. Genome-wide association study of antidepressant response: involvement of the inorganic cation transmembrane transporter activity pathway. Bmc Psychiatry 2016, 16, 106. 
268. Breitenkamp, A.F.; Matthes, J.; Nass, R.; Sinzig, J.; Lehmkuhl, G.; Nürnberg, P.; Herzig, S. Rare Mutations of CACNB2 Found in Autism Spectrum Disease-Affected Families Alter Calcium Channel Function. PLoS ONE 2014, 9, e95579.

269. Yuen, R.K.; Thiruvahindrapuram, B.; Merico, D.; Walker, S.; Tammimies, K.; Hoang, N.; Chrysler, C.; Nalpathamkalam, T.; Pellecchia, G.; Liu, Y.; et al. Whole-genome sequencing of quartet families with autism spectrum disorder. Nat Med 2015, 21, 185-191.

270. Psychiatric GWAS consortium Bipolar Disorder Working Group ; Sklar, P.; Ripke, S.;

Scott, L.J.; Andreassen, O.A.; Cichon, S.; Craddock, N.; Edenberg, H.J.; Jr, J.I.; Rietschel, M.; et al. Large-scale genome-wide association analysis of bipolar disorder identifies a new susceptibility locus near ODZ4. Nature Genetics 2011, 43, 977.

271. Shenker, J.J.; ngupta, S.; Joober, R.; Malla, A.; Chakravarty, M.M.; Lepage, M. Bipolar disorder risk gene FOXO6 modulates negative symptoms in schizophrenia: a neuroimaging genetics study. J Psychiatry Neurosci Jpn 2017, 42, 172-180.

272. van Hulzen, K.; Scholz, C.J.; Franke, B.; Ripke, S.; Klein, M.; McQuillin, A.; SonugaBarke, E.J.; Group, P.; Kelsoe, J.R.; Landén, M.; et al. Genetic Overlap Between AttentionDeficit/Hyperactivity Disorder and Bipolar Disorder: Evidence From Genome-wide Association Study Meta-analysis. Biol Psychiat 2017, 82, 634-641.

273. Maycox, P.; Kelly, F.; Taylor, A.; Bates, S.; Reid, J.; Logendra, R.; Barnes, M.; Larminie, 
C.; Jones, N.; Lennon, M.; et al. Analysis of gene expression in two large schizophrenia cohorts identifies multiple changes associated with nerve terminal function. Mol Psychiatr 2009, 14, 1083.

274. Müller, C.; Haupt, A.; Bildl, W.; Schindler, J.; Knaus, H.-G.; Meissner, M.; Rammner, B.; Striessnig, J.; Flockerzi, V.; Fakler, B.; et al. Quantitative proteomics of the Cav2 channel nanoenvironments in the mammalian brain. Proceedings of the National Academy of Sciences 2010, $107,14950-14957$.

275. Coleman, J.R.; Lester, K.J.; Keers, R.; Roberts, S.; Curtis, C.; Arendt, K.; Bögels, S.; Cooper, P.; Creswell, C.; Dalgleish, T.; et al. Genome-wide association study of response to cognitive-behavioural therapy in children with anxiety disorders. Brit J Psychiat 2016, 209, 236-243.

276. Landmark, C.; Beiske, G.; Baftiu, A.; Burns, M.L.; Johannessen, S.I. Experience from therapeutic drug monitoring and gender aspects of gabapentin and pregabalin in clinical practice. Seizure 2015, 28, 88-91.

277. Sofuoglu, M.; Rosenheck, R.; Petrakis, I. Pharmacological treatment of comorbid PTSD and substance use disorder: Recent progress. Addictive Behaviors 2014, 39, 428-433.

278. Stefani, A.; Spadoni, F.; Siniscalchi, A.; Bernardi, G. Lamotrigine inhibits Ca2+ currents in cortical neurons: functional implications. Eur J Pharmacol 1996, 307, 113-116. 
279. Weiergräber, M.; Henry, M.; Radhakrishnan, K.; Hescheler, J.; Schneider, T. Hippocampal seizure resistance and reduced neuronal excitotoxicity in mice lacking the Cav2.3 E/R-type voltage-gated calcium channel. Journal of neurophysiology 2007, 97, 3660-9.

280. Xu, J.; Yabuki, Y.; Yu, M.; Fukunaga, K. T-type calcium channel enhancer SAK3 produces anti-depressant-like effects by promoting adult hippocampal neurogenesis in olfactory bulbectomized mice. Journal of pharmacological sciences 2018, 137, 333-341.

281. Wang, S.; Yabuki, Y.; Matsuo, K.; Xu, J.; Izumi, H.; Sakimura, K.; Saito, T.; Saido, T.C.; Fukunaga, K. T-type calcium channel enhancer SAK3 promotes dopamine and serotonin releases in the hippocampus in naive and amyloid precursor protein knock-in mice. PloS one 2018, 13, e0206986. 